\title{
Different Doses of $\beta$-Cryptoxanthin May Secure the Retina from Photooxidative Injury Resulted from Common LED Sources
}

\author{
Cemal Orhan, ${ }^{1}$ Mehmet Tuzcu, ${ }^{2}$ Hasan Gencoglu, ${ }^{2}$ Emre Sahin, ${ }^{1}$ Nurhan Sahin, ${ }^{1}$ \\ Ibrahim Hanifi Ozercan, ${ }^{3}$ Tejas Namjoshi, ${ }^{4}$ Vandita Srivastava, ${ }^{4}$ Abhijeet Morde, ${ }^{5}$ \\ Deshanie Rai, ${ }^{6}$ Muralidhara Padigaru, ${ }^{5}$ and Kazim Sahin $\mathbb{D}^{1}$ \\ ${ }^{1}$ Department of Animal Nutrition, Faculty of Veterinary Science, Firat University, Elazig 23119, Turkey \\ ${ }^{2}$ Division of Biology, Faculty of Science, Firat University, Elazig 23119, Turkey \\ ${ }^{3}$ Department of Pathology, Faculty of Medicine, Firat University, Elazig 23119, Turkey \\ ${ }^{4}$ OmniActive Health Technologies, Biotechnology Park, Pune 411057, India \\ ${ }^{5}$ OmniActive Health Technologies, Wagle Estate, Thane 400604, India \\ ${ }^{6}$ OmniActive Health Technologies Inc, Morristown, NJ 07960, USA
}

Correspondence should be addressed to Kazim Sahin; nsahinkm@yahoo.com

Received 9 October 2020; Revised 27 January 2021; Accepted 1 February 2021; Published 10 February 2021

Academic Editor: Daoud Ali

Copyright @ 2021 Cemal Orhan et al. This is an open access article distributed under the Creative Commons Attribution License, which permits unrestricted use, distribution, and reproduction in any medium, provided the original work is properly cited.

Retinal damage associated with loss of photoreceptors is a hallmark of eye diseases such as age-related macular degeneration (AMD) and diabetic retinopathy. Potent nutritional antioxidants were previously shown to abate the degenerative process in AMD. $\beta$-Cryptoxanthin (BCX) is an essential dietary carotenoid with antioxidant, anti-inflammatory, and provitamin A activity. It is a potential candidate for developing intervention strategies to delay the development/progression of AMD. In the current study, the effect of a novel, highly purified BCX oral formulation on the rat retinal damage model was evaluated. Rats were fed with BCX for four weeks at the doses of 2 and $4 \mathrm{mg} / \mathrm{kg}$ body weight in the form of highly bioavailable oil suspension, followed by retinal damage by exposing to the bright light-emitting diode (LED) light (750 lux) for $48 \mathrm{hrs}$. Animals were sacrificed after 48 hours, and eyes and blood samples were collected and analyzed. BCX supplementations (2 and $4 \mathrm{mg} / \mathrm{kg})$ showed improvements in the visual condition as demonstrated by histopathology of the retina and measured parameters such as total retinal thickness and outer nuclear layer thickness. BCX supplementation helped reduce the burden of oxidative stress as seen by decreased serum and retinal tissue levels of malondialdehyde (MDA) and restored the antioxidant enzyme activities in BCX groups. Further, BCX supplementation modulated inflammatory markers (IL-1 $\beta$, IL-6, and NF- $\kappa$ B), apoptotic proteins (Bax, Bcl-2, caspase 3), growth proteins and factors (GAP43, VEGF), glial and neuronal proteins (GFAP, NCAM), and heme oxygenase-1 (HO-1), along with the mitochondrial stress markers (ATF4, ATF6, Grp78, Grp94) in the rat retinal tissue. This study indicates that oral supplementation of BCX exerts a protective effect on light-induced retinal damage in the rats via reducing oxidative stress and inflammation, also protected against mitochondrial DNA damage and cellular death.

\section{Introduction}

Light-induced degeneration of photoreceptor cells and the disease's progression in the age-related macular degeneration (AMD) comprise the oxidative damage and, eventually, visual cell loss, which can be inhibited or decelerated by the contribution of antioxidants [1,2]. Accumulation of drusen and $\beta$-amyloid peptides in the subretinal space resulting in inflammation and photoreceptor degeneration is observed in early AMD [3]. Further, oxidative stress, inflammation, cell damage leading to cell death, and mitochondrial DNA damage are cellular processes associated with AMD [4]. However, the crucial photobiological role of ultraviolet lights (UVB and UVA) induced apoptosis and cytotoxic damage in DNA prevention was documented in earlier reports $[5,6]$. The retina is one of the tissues that consume the most oxygen in the human body [7]. Oxidative stress and inflammation governed by the activation of nuclear factor kappa B (NF- 
$\kappa \mathrm{B})$ have been suggested to mediate crucial parts in retinopathy's pathogenesis [8]. Even though light-emitting diode (LED) usage has advantages like low energy expenditure and longer lifetime, concerns have been raised due to the harmful blue region of the light spectrum from white LEDs, which can cause eventual retinal damage and toxicity because of their intense emission [9].

It has been shown that some carotenoids, such as lutein and zeaxanthin that are located in the macula and retina, have useful properties against oxidative stress and are also protect against photooxidative damage [10-13]. To protect the retinal pigment epithelium against the photooxidative damage, carotenoids are proposed to act through two primary mechanisms: firstly, carotenoids help to filter harmful blue light and, secondly, remove the triple-state molecules, singlet molecular oxygen, and reactive oxygen species such as lipid peroxides and superoxide radical anions $[13,14]$.

Humans and animals cannot synthesize carotenoids, and they have to get them from dietary origins like fruits and vegetables [15]. Many findings from the various studies have shown that $\beta$-cryptoxanthin (BCX) has reasonably high bioavailability from its mutual nutritive origins, to the extent that some foods rich in BCX might be equal to or better than $\beta$-carotene-rich foods as retinol sources [16]. BCX is a provitamin A polar carotenoid (xanthophyll), and its selective uptake and deposition as a macular xanthophyll in the retina and brain are enhanced by specific xanthophyll-binding proteins [17]. Carotenoid oxygenases are suggested to be used by mammals for the retinoid synthesis from provitamin A carotenoids [18]. BCX is thought to be cleaved in the metabolism via the provitamin A-converting enzymes, involving both cytosolic $\beta$-carotene oxygenase 1 (BCO1) and mitochondrial $\mathrm{BCO} 2$, through a multistep process $[18,19]$.

Comprehending the molecular mechanisms of retinal light injury in the animal models can yield vital information concerning the effects of light in clinical diseases and can be the basis for future treatments to inhibit or delay visual cell loss [20, 21], impaired vision performance, and eye diseases such as AMD. Given that BCX is an efficient provitamin A carotenoid with potent antioxidant effects $[16,22]$ and in light of the role of vitamin A in eye health and vision performance, including dark adaptation. Hence, it was our main interest to understand if and how BCX can play a role in limiting the mechanistic pathways mediating light-induced retinal injury and photooxidative stress. Therefore, our study measured the effectiveness of BCX using the damaged retinal model on a variety of oxidant and antioxidant biochemical and inflammatory markers. These included interleukin- $1 \beta$ (IL-1 $\beta$ ), interleukin-6 (IL-6), NF- $\kappa$ B; apoptotic proteins; Bcell lymphoma 2 (Bcl-2), Bcl-2-associated X protein (Bax), cysteine-aspartic acid protease-3 (caspase-3); notable proteins and molecules like growth-associated protein 43 (GAP43), glial fibrillary acidic protein (GFAP), neural cell adhesion molecule (NCAM), heme oxygenase-1 (HO-1), vascular endothelial growth factor (VEGF) and the endoplas$\mathrm{mic}$ reticulum/mitochondrial stress markers such as activating transcription factor 4 and 6 (ATF4, ATF6), and glucose-regulated proteins 78 and 94 (Grp78, Grp94). Furthermore, we have also evaluated the effects of BCX on the retinal layer pathology, BCX, and retinol changes in the serum and retina of the rats exposed to intense LED illuminance.

\section{Materials and Methods}

2.1. Animals and Diets. Twenty-eight Wistar Albino male rats, age: 8 weeks, weight: $180 \pm 20 \mathrm{~g}$, were housed in a controlled environment with a $12: 12$-h light-dark cycle at $22^{\circ} \mathrm{C}$ and were provided with standard rat chow (Table 1) and tap water ad libitum. All the experiments were conducted under the National Institutes of Health's Guidelines for the Care and Use of Laboratory Animals and approved by the Firat University Ethics Committee, Elazig (2019-94-143). After providing compliance with the laboratory conditions, rats were randomly divided into four treatment groups, each containing seven animals.

Animals were orally administered with BCX for four weeks followed by 48 hrs ( 12 hours light/12 hours dark periods) to induce retinal degeneration (RD) with LED light illumination (750 lux), and animals were continued on BCX supplementation during these two days of light exposure. Before intense light exposure, pupils of the animals were dilated with $1 \%$ tropicamide, and after exposure, animals were kept in the dark until evaluation. BCX $\left(\mathrm{BCXcel}^{\mathrm{TM}}\right)$ was supplied by OmniActive Health Technologies Pvt. Ltd., Mumbai, India (B.No:141025). BCX concentrate was derived from Paprika oleoresin by solvent extraction and column chromatography. BCX concentrate, which contained about $10-80 \%$ by weight total xanthophyll, of which about $75-$ $98 \%$ by weight was trans-beta-cryptoxanthin, the remaining including zeaxanthin, trans-capsanthin, beta-carotene, and trace amounts of other carotenoids, derived from oleoresin. The active ingredient ( $\beta$-cryptoxanthin) was analyzed by UV spectrophotometer (Shimadzu UV-1800) and Agilent 1200 HPLC System (Agilent Technologies, Santa Clara, CA, USA). For sample preparation, $100 \mathrm{mg}$ sample was weighed, $30 \mathrm{~mL}$ of tetrahydrofuran was added in 100-mL ambercolored volumetric flask and sonicated till sample is dissolved with intermediate shaking. After cooling, a volume of up to $100 \mathrm{~mL}$ was made with ethyl acetate (sample stock solution A). Next, the extract was pipetted with $5.0 \mathrm{~mL}$ of sample stock solution A into a $25-\mathrm{mL}$ volumetric flask, diluted with the mobile phase, and filtered through a 0.45 -micron filter. The sample was then run with an HPLC system using YMC- Carotenoid S5 micron $(250 \mathrm{mmx} 4.6 \mathrm{~mm})$ column and mobile phase methanol: chloroform 900:100 at a flow rate of $1.5 \mathrm{~mL} / \mathrm{min}$. Chromatograms were examined at $451 \mathrm{~nm}$, and the injection volume was $20 \mu \mathrm{l}$. Mixed tocopherol $(0.3 \%)$ was added to the oil suspension as an antioxidant.

2.2. Experimental Design. The experimental design of the groups is summarized in Table 2 . The rats were divided into four groups: (i) standard control: these animals only received standard rat chow and tap water ad until the end of the study; (ii) retinal degeneration (RD): fed as the control group, but remained under intense LED lighting for 48 hours after four weeks of the study; (iii) $\beta$-cryptoxanthin 1 (BCX1): fed as the control group and given BCX intragastrically by oral gavage 
TABLE 1: Ingredients and chemical analysis of the standard diet.

\begin{tabular}{lc}
\hline Ingredients & Quantity $(\%)$ \\
\hline Maize & 30.22 \\
Barley & 10.07 \\
Soybean meal & 38.28 \\
Sunflower seed meal & 6.04 \\
Wheat bran & 10.08 \\
Molasses & 3.02 \\
Limestone & 1.51 \\
Salt & 0.08 \\
DL-Methionine & 0.30 \\
Dicalcium phosphate & 0.20 \\
Vitamin-mineral premix $*$ & 0.20 \\
Chemical analysis & \\
Crude protein \% & 24.00 \\
Metabolizable energy $\left(\mathrm{kcal} / \mathrm{kg}^{* *}\right)$ & 3100 \\
Ether extract \% & 3.40 \\
Crude cellulose \% & 6.90 \\
Ash \% & 8.10 \\
Calcium \% & 1.30 \\
Phosphorus \% & 0.90 \\
\hline In per kilogm of & \\
\hline
\end{tabular}

* In per kilogram of vitamin-mineral mixture: $1.8 \mathrm{mg}$ all-trans retinyl acetate (vitamin A), $0.025 \mathrm{mg}$ cholecalciferol (vitamin D), $12.5 \mathrm{mg}$ whole rac-alphatocopherol acetate (vitamin E), $1.1 \mathrm{mg}$ menadione sodium bisulfite (vitamin $\mathrm{K} 3$ ), $1.1 \mathrm{mg}$ thiamine (vitamin B1), $4.4 \mathrm{mg}$ riboflavin (vitamin B2), $35 \mathrm{mg}$ niacin (vitamin B3), $10 \mathrm{mg}$ calcium pantothenate (vitamin B5), $2.2 \mathrm{mg}$ vitamin B6, 0.02 vitamin B12, $0.55 \mathrm{mg}$ folic acid, $0.1 \mathrm{mg}$ d-biotin, $40 \mathrm{mg}$ $\mathrm{Mn}(\mathrm{MnO}), 12.5 \mathrm{mg} \mathrm{Fe}(\mathrm{FeSO} 4), 25 \mathrm{mg} \mathrm{Zn}(\mathrm{ZnO}), 3.5 \mathrm{mg} \mathrm{Cu}(\mathrm{CuSO} 4)$, $0.3 \mathrm{mg}$ I (KI), $0.15 \mathrm{mg}$ Se (Na2SeO3), $175 \mathrm{mg}$ choline chlorite (C5H14ClNO). ${ }^{* *}$ Metabolic energy was calculated according to the National Research Council [71].

( $2 \mathrm{mg} / \mathrm{kg}$ BW/day) then remained under intense LED lighting for 48 hours after the four weeks of the study; (iv) $\beta$-cryptoxanthin 2 (BCX2): fed as the control group and given $\mathrm{BCX}$ intragastrically by oral gavage $(4 \mathrm{mg} / \mathrm{kg}$ BW/day) then remained under intense LED lighting for 48 hours after the four weeks of the study. The doses of BCX were chosen from a previous study (Sahin et al. 2017). BCX application was also continued during the 48 hours with intensive lighting. Oral gavage is commonly used to deliver substances to animals in pharmacological and toxicological studies [23]. To ensure standardized dosage and to prevent inadvertent oxidation, delivery of the treatment (BCX or corn oil) was administered by oral gavage. Oral gavage was carried out by using a curved metal needle with a bulbed tip. All gavage procedures were carried out once per day at a similar time of day without administering any anesthesia (between 8.30 a.m. and 10:30 a.m.) for $6 \mathrm{~d}$ per week over four consecutive weeks. BCX was dissolved in corn oil. The control group received corn oil in a similar condition to the treatment of other experimental groups.

For an intense light exposure experiment, each rat was kept in an isolated cage. White light-emitting diodes were placed on the top of the shelves and were measured at a distance of $20 \mathrm{~cm}$ from the remote source to achieve 750 lux standard indoor lighting levels for all groups [24]. To allow retinal degeneration to occur, animals were placed in an environmentally organized light stress box equipped with 750 lux of diffuse white LEDs fixed on the inner upper surface, which lightened the inner walls. Animals were sacrificed by cervical dislocation under xylazine $(10 \mathrm{mg} / \mathrm{kg}$, i.m.) and ketamine ( $50 \mathrm{mg} / \mathrm{kg}$, i.m.) anesthesia immediately following the light and dark exposures; eyes were removed and blood tissue collected.

2.3. Biochemical Analysis. Immediately after collecting the target samples, blood tissue was centrifuged at $5000 \mathrm{rpm}$ for obtaining the serum. Serum biochemical parameters (glucose, BUN, and ALT and AST) were examined with a biochemistry analyzer (Samsung Co., Suwon, Korea). Tissues were rinsed with $0.5 \mathrm{~mL}$ of a phosphate buffer saline solution ( $\mathrm{pH}$ 7.4). Tissues were then homogenized in $5-10 \mathrm{~mL}$ of cold buffer [20 mM HEPES buffer, pH7.2 containing $1 \mathrm{mM}$ EGTA, $210 \mathrm{mM}$ mannitol and $70 \mathrm{mM}$ sucrose for superoxide dismutase (SOD), $50 \mathrm{nM}$ potassium phosphate, $\mathrm{pH}$ 7.0, containing $1 \mathrm{mM}$ EDTA for catalase (CAT), and $50 \mathrm{mM}$ TrisHCI, pH 7.5, $5 \mathrm{mM}$ EDTA, and $1 \mathrm{mM}$ DTT for glutathione peroxidase (GSH-Px)] per gram tissue for each enzyme assay. Homogenates were centrifuged at $10,000 \times \mathrm{g}$ at $4^{\circ} \mathrm{C}$ for $15 \mathrm{~min}$ for CAT and GSHPx and centrifuged at $1,500 \times \mathrm{g}$ for $5 \mathrm{~min}$ at $4^{\circ} \mathrm{C}$ for SOD. Supernatants were then removed and assayed for enzyme activities using the commercial kits (Cayman Chemical, Ann Arbor, MI, USA) depending on the colorimetric methods, which were then measured with a highly sensitive Enzyme-Linked Immunosorbent Assay (ELISA) spectrophotometry reader (ELx800 ${ }^{\mathrm{TM}}$ Absorbance Microplate Reader (BioTek Instruments Winooski VT) according to the manufacturer's procedure (Cayman Chemical, Ann Arbor, MI, USA). The protein concentrations were indicated by the Bradford method using Bradford reagent (Sigma Aldrich, Bradford reagent-B6916-1KT, USA). The intra- and interassay coefficients of variation (CV) for SOD, CAT, and GSH-Px were $3.2 \%$ and $3.7 \%, 3.8 \%$ and $9.9 \%$, and $5.7 \%$ and $7.2 \%$, respectively.

For MDA analyses, samples were homogenized in a mixture of $0.5 \mathrm{~mL}$ of $\mathrm{HClO}_{4}(0.5 \mathrm{M}), 2.5 \mathrm{~mL}$ distilled water, and 2[6]-di-tert-butyl-p-cresol (BHT) for precipitating proteins and releasing the MDA bound to the amino groups of proteins and other amino compounds. The samples were then centrifuged at $4500 \mathrm{rpm}$ for $5 \mathrm{~min}$, and supernatants were injected into the HPLC system. For this purpose, an HPLC apparatus of Shimadzu UV-vis SPD-10 AVP detector, a CTO-10 AS VP column, and $30 \mathrm{mM} \mathrm{KH}_{2} \mathrm{PO}_{4}$ and methanol (82.5: 17.5, v/v, pH 3.6) at a flow rate of $1 \mathrm{~mL} / \mathrm{min}$ were used (Shimadzu, Kyoto Japan). Chromatograms were monitored at $250 \mathrm{~nm}$, and the injection volume was $20 \mu \mathrm{l}[25,26]$.

Serum and retinal tissue BCX and retinol levels were also analyzed by using HPLC. Samples were homogenized in $1 \mathrm{~mL}$ of cold acetone. Homogenized samples were transferred into polyethylene tubes, and $2 \mathrm{~mL}$ ethanol was added to the tubes. After $0.3 \mathrm{~mL}$-hexane was filled into tubes for extractions, they were centrifuged. This step was repeated three times. N-hexane in tubes was evaporated, and the residues were solved in the mobile phase (methanol:acetonitrile:chloroform; $47: 42: 11, v / v)$ [25]. 
TABLE 2: Experimental design of the study.

\begin{tabular}{|c|c|c|c|c|}
\hline Groups & $\begin{array}{l}\text { Standard control } \\
\qquad n=7\end{array}$ & $\begin{array}{l}\text { RD control } \\
n=7\end{array}$ & $\begin{array}{c}\text { RD+BCX1 } \\
\text { Dose level } 1 \\
n=7\end{array}$ & $\begin{array}{c}\mathrm{RD}+\mathrm{BCX} 2 \\
\text { Dose level } 2 \\
n=7\end{array}$ \\
\hline Dose & - & - & $\begin{array}{l}2 \mathrm{mg} / \mathrm{kg} \mathrm{BW} \text { of active } \beta \text { - } \\
\text { cryptoxanthin }\end{array}$ & $\begin{array}{l}4 \mathrm{mg} / \mathrm{kg} \mathrm{BW} \text { of active } \beta \text { - } \\
\text { cryptoxanthin }\end{array}$ \\
\hline $\begin{array}{l}\text { LED } \\
\text { illumination }\end{array}$ & - & $\begin{array}{c}\text { Intense LED light (750 lux) } \\
\text { Exposure for } 48 \text { hours after four } \\
\text { weeks }\end{array}$ & $\begin{array}{c}\text { Intense LED light (750 lux) } \\
\text { Exposure for } 48 \text { hours after four } \\
\text { weeks }\end{array}$ & $\begin{array}{c}\text { Intense LED light (750 lux) } \\
\text { Exposure for } 48 \text { hours after four } \\
\text { weeks }\end{array}$ \\
\hline
\end{tabular}

BCX: $\beta$-cryptoxanthin; BW: Body Weight; LED: Light Emitting Diode; RD: Retinal Degeneration.

2.4. Histopathological Analysis. After the eye removal of each rat, the retinas were examined grossly. The tissue was then removed for histological study, washed with plain ordinary saline, immersion-fixed (4\% paraformaldehyde and then paraffin), and sectioned into $5-\mu \mathrm{m}$ thick slices using a microtome. Retinal tissues were stained with hematoxylin and eosin (H\&E) and examined using light microscopy. The retinal histology was performed for all the groups with slight modifications as defined earlier [27]. The tissue's midsuperior aspect was examined for all histological analyses through a light microscope at 100x (Olympus, BX51, Japan). Retinal edema damage caused by an intense LED light is graded as follows: $(+)$ mild, $(++)$ moderate, and $(+++)$ rated as severe edema.

2.5. Western Blot Analysis. Target proteins were detected via western blotting with slight modifications as previously described in detail $[28,29]$. The retinal interleukin- $\beta$ (IL$1 \beta$ ), interleukin-6 (IL-6), NF- $\kappa \mathrm{B}$; apoptotic proteins; B-cell lymphoma 2 (Bcl-2), Bcl-2-associated X protein (Bax), cysteine-aspartic acid protease-3 (caspase-3); notable proteins and molecules like growth-associated protein 43 (GAP43), glial fibrillary acidic protein (GFAP), neural cell adhesion molecule (NCAM), heme oxygenase-1 (HO-1), vascular endothelial growth factor (VEGF) and the endoplasmic reticulum/mitochondrial stress markers such as activating transcription factor 4 and 6 (ATF4, ATF6), and glucose-regulated proteins 78 and 94 (Grp78, Grp94), and actin (as a reference protein to control protein loading) were targeted. Briefly, after the homogenization, each group of animals was examined in triplicates for each experimental situation. $20-50 \mu \mathrm{g}$ of total proteins was transferred to a nitrocellulose membrane (Schleicher and Schuell Inc., Keene, $\mathrm{NH}$, USA) via immunoblotting after the electrophoresis using Bio-Rad Mini-Protean Tetra electrophoresis "wettransfer" system (Bio-Rad, California, USA). The phosphorylated form of antibodies against IL- $1 \beta$, IL-6, NF- $\kappa$ B, VEGF, Bax, Bcl2, Caspase-3, GAP43, GFAP, NCAM, HO-1, ATF4, ATF6, Grp78, and Grp94 (Abcam, Cambridge, UK) was diluted in a concentration of $(1: 1000-1: 2000)$ in a PBS buffer which contains $0.05 \%$ of tween 20 . The loading of proteins was checked by a monoclonal mouse antibody against $\beta$-actin (A5316; Sigma). Blots were performed at least three times to confirm the reproducibility of the results. Bands were analyzed densitometrically using an image analysis system (Image J; National Institute of Health, Bethesda, USA).
2.6. Statistical Analysis. The sample size of the study was determined as 28 rats for all groups (7 animals per group) with the help of the $\mathrm{G} *$ Power package program (Version 3.1.9.2) with alpha error 0.05 and $85 \%$ power with an effect size of 0.69 [30]. Conformity to the normality assumption from the prerequisites of the parametric tests was performed using the "Shapiro-Wilk" test. The homogeneity of the variances was checked with the "Levene" test. Analysis of variance (ANOVA) test was performed to determine the differences between the groups, and post hoc Tukey test was used for multiple comparisons of the groups. All analyzes performed using the SPSS statistical program (IBM, SPPS Version 21). $p$ values $<0.05$ were considered significant. Data is presented as mean and standard deviation.

\section{Results}

The effects of BCX1 and BCX2 supplementation on the serum biochemical parameters are presented in Table 3. BCXcel $^{\mathrm{TM}}$ supplementation did not change the serum levels of glucose $(p=0.890)$, creatinine $(p=0.953)$, blood urea nitrogen (BUN) $(p=0.654)$, total protein (TP) $(p=0.661)$, albumin (ALB) $(p=0.725)$, globulin (GLOB) $(p=0.955)$, and activities of alanine aminotransferase (ALT) $(p=0.698$ ) , aspartate aminotransferase (AST) $(p=0.866)$, alkaline phosphatase (ALP) $(p=0.892)$, and total bilirubin (TBIL) level $(p=0.101)$, in all the groups of rats $(p>0.05)$. Changes in serum and retina activities of SOD, GSH-Px, CAT, and MDA, BCX, and retinol levels during intense LED lightinduced retinal degeneration between the groups are presented in Table 4. Accordingly, serum and retina MDA levels were the highest in the RD group, while BCX1 and BCX2 administration significantly decreased serum and retinal tissue MDA levels $(p<0.0001)$. Retina SOD, GSHPx, and CAT activities were measured at the highest levels in the control group, while the lowest values were determined in the $\mathrm{RD}$ group $(p<0.05)$. However, BCX administration significantly increased antioxidant enzymes' retinal activities, especially the BCX2 dose, which was more effective $(p<0.001)$. Serum and retina BCX levels were not detected in the control and $\mathrm{RD}$ groups, while in the BCX2 group, serum levels were 2.3 times, and retinal levels were 2.8 times higher than the BCX1 group $(p<0.05)$. Serum and retina retinol levels were found in the lowest number in the $\mathrm{RD}$ groups, whereas BCX2, BCX1, and control groups were found in higher amounts, respectively $(p<0.05)$. 
TABLE 3: Effects of BCX supplementation on serum biochemical parameters in rats exposed to LED light.

\begin{tabular}{|c|c|c|c|c|c|}
\hline \multirow{2}{*}{ Items } & \multicolumn{4}{|c|}{ Groups } & \multirow{2}{*}{$p^{*}$} \\
\hline & Control & $\mathrm{RD}$ & $\mathrm{RD}+\mathrm{BCX} 1$ & $\mathrm{RD}+\mathrm{BCX} 2$ & \\
\hline Glucose, mg/dL & $119.71 \pm 8.12$ & $120.43 \pm 8.08$ & $117.71 \pm 13.62$ & $122.06 \pm 10.92$ & 0.890 \\
\hline Creatinine, $\mathrm{mg} / \mathrm{dL}$ & $0.41 \pm 0.11$ & $0.42 \pm 0.12$ & $0.39 \pm 0.09$ & $0.41 \pm 0.14$ & 0.953 \\
\hline BUN, mg/dL & $21.96 \pm 1.89$ & $22.91 \pm 1.38$ & $23.04 \pm 2.66$ & $22.34 \pm 0.75$ & 0.654 \\
\hline $\mathrm{TP}, \mathrm{g} / \mathrm{dL}$ & $7.47 \pm 0.77$ & $7.01 \pm 0.51$ & $7.30 \pm 1.00$ & $7.41 \pm 0.55$ & 0.661 \\
\hline $\mathrm{ALB}, \mathrm{g} / \mathrm{dL}$ & $3.57 \pm 0.34$ & $3.39 \pm 0.46$ & $3.49 \pm 0.30$ & $3.57 \pm 0.28$ & 0.725 \\
\hline GLOB, g/dL & $3.76 \pm 0.46$ & $3.83 \pm 0.47$ & $3.71 \pm 0.68$ & $3.69 \pm 0.32$ & 0.955 \\
\hline ALT, U/L & $71.14 \pm 5.64$ & $68.71 \pm 4.61$ & $67.86 \pm 5.64$ & $72.43 \pm 13.25$ & 0.698 \\
\hline AST, U/L & $91.29 \pm 7.06$ & $96.43 \pm 16.30$ & $92.29 \pm 9.89$ & $95.71 \pm 17.95$ & 0.866 \\
\hline ALP, U/L & $132.57 \pm 9.50$ & $130.29 \pm 14.50$ & $135.57 \pm 21.03$ & $137 \pm 22.35$ & 0.892 \\
\hline TBIL, mg/dL & $0.21 \pm 0.02$ & $0.22 \pm 0.02$ & $0.23 \pm 0.02$ & $0.24 \pm 0.03$ & 0.101 \\
\hline
\end{tabular}

BCX: $\beta$-cryptoxanthin; BUN: blood urea nitrogen; TP: total protein; ALB: albumin; GLOB: globulin; ALT: alanine aminotransferase; AST: aspartate aminotransferase; ALP: alkaline phosphatase; TBIL: total bilirubin; RD: retinal degeneration. Data are presented as means and standard deviations. Means in the same line without a common superscript differ significantly $\left(p<.05 ;{ }^{*}\right.$ ANOVA and Tukey's post hoc test).

TABLE 4: Effects of BCX supplementation on MDA, BCX, retinol levels, and antioxidant enzyme activities in rats exposed to LED light.

\begin{tabular}{lcccc}
\hline Markers & Control & GD & RD+BCX1 & RD+BCX2 \\
\hline Serum MDA, nmol/mL & $0.45 \pm 0.08^{\mathrm{c}}$ & $1.19 \pm 0.17^{\mathrm{a}}$ & $0.79 \pm 0.12^{\mathrm{b}}$ & $0.64 \pm 0.07^{\mathrm{b}}$ \\
Retina MDA, nmol/mg & $0.8 \pm 0.11^{\mathrm{d}}$ & $1.81 \pm 0.12^{\mathrm{a}}$ & $1.51 \pm 0.08^{\mathrm{b}}$ & $1.12 \pm 0.15^{\mathrm{c}}$ \\
Retina SOD, U/mg protein & $85.34 \pm 6.57^{\mathrm{a}}$ & $56.71 \pm 7.11^{\mathrm{c}}$ & $65.9 \pm 4.77^{\mathrm{bc}}$ & $75.13 \pm 6.74^{\mathrm{b}}$ \\
Retina GSH-Px, U/mg protein & $29.48 \pm 1.83^{\mathrm{a}}$ & $14.29 \pm 1.78^{\mathrm{d}}$ & $19.16 \pm 1.62^{\mathrm{c}}$ & $23.74 \pm 2.23^{\mathrm{b}}$ \\
Retina CAT, U/mg protein & $33.96 \pm 3.9^{\mathrm{a}}$ & $13.88 \pm 1.5^{\mathrm{c}}$ & $20.84 \pm 3.15^{\mathrm{b}}$ & $25.2 \pm 3.39^{\mathrm{b}}$ \\
Serum BCX, nmol/L & - & - & $6.86 \pm 1.35^{\mathrm{b}}$ & $15.83 \pm 1.83^{\mathrm{a}}$ \\
Retina BCX, nmol/g & - & - & $0.2 \pm 0.08^{\mathrm{b}}$ & $0.56 \pm 0.11^{\mathrm{a}}$ \\
Serum retinol, ng/mL & $275.49 \pm 27.91^{\mathrm{ab}}$ & $240.43 \pm 20.61^{\mathrm{b}}$ & $282.87 \pm 19.57^{\mathrm{a}}$ & $288.3 \pm 27.9^{\mathrm{a}}$ \\
Retina retinol, $\mu \mathrm{g} / \mathrm{g}$ & $5.69 \pm 0.97$ & $4.75 \pm 0.81$ & $5.87 \pm 1.07$ & $5.92 \pm 1.34$ \\
\hline
\end{tabular}

The data are presented as means \pm standard deviations. Mean values in the same row without a common superscript (a-d) differ significantly $(p<.05)$. BCX: $\beta$ cryptoxanthin; MDA: malondialdehyde; RD: retinal degeneration; SOD: superoxide dismutase; GSH-Px: glutathione peroxidase; CAT: catalase.

A representative image showing the histopathological effect of both doses of BCXcel ${ }^{\mathrm{TM}}$ supplementation on intense LED light-induced retinal degeneration is presented in Figure 1 . The retina had a normal histological appearance in the control group. In the RD group, severe edema (+++) was observed in the ganglion layer of the retina, and significant thickening was observed in the outer plexiform layer of the retina. In the $\mathrm{RD}+\mathrm{BCX} 1$ group, edema decreased in the ganglion layer $(++)$, and there was a slight decrease in the thickening of the outer plexiform layer of the retina. In the $\mathrm{RD}+\mathrm{BCX} 2$ group, very mild edema $(+)$ near the normal was observed in the ganglion layer, and a marked decrease in the thickening of the outer plexiform layer of the retina was observed. Figure 2 demonstrates that four weeks of $\mathrm{BCXcel}^{\mathrm{TM}}$ supplementation significantly preserved the quantifications of both retinal thickness and the ONL thickness of the intense LED light-exposed rats, compared with the control and RD groups $(p<.05)$.

The effects of both doses of BCXcel ${ }^{\mathrm{TM}}$ supplementation on the levels of inflammatory genes, IL- $1 \beta$, IL- 6 , and NF- $\kappa \mathrm{B}$ along with VEGF, are shown in Figure 3. RD group showed significantly more IL- $1 \beta$, IL- $6, \mathrm{NF}-\kappa \mathrm{B}$ levels in all groups compared to other groups $(p<0.001)$; however, BCXcel ${ }^{\mathrm{TM}}$ supplementation significantly decreased these levels while bringing them closer to control levels, especially in the group administered with BCX $(p<0.001)$. Also, retina VEGF levels were found higher in control, while the RD and BCX1/BCX2 groups decreased significantly $(p<0.0001)$. Figure 4 shows the effects of two doses of BCXcel ${ }^{\mathrm{TM}}$ on Bax, Bcl-2, Caspase3, Gap43, GFAP, NCAM, and HO-1 retinal protein levels in rats. Proapoptotic proteins Bax and Caspase- 3 retina levels were upregulated depending on the amount of $\mathrm{BCXcel}^{\mathrm{TM}}$ supplement $(p<0.001)$, whereas the antiapoptotic Bcl-2 levels were found to be downregulated $(p<0.0001)$. While GAP43 levels decreased significantly in all groups compared to the control group $(p<0.01)$, it was significantly lower in the BCX2 group compared to the RD group $(p<0.05)$. GFAP levels showed the most significant increase in the RD group compared to all groups $(p<0.001)$, while BCX application decreased these levels significantly $(p<0.001)$, and there 


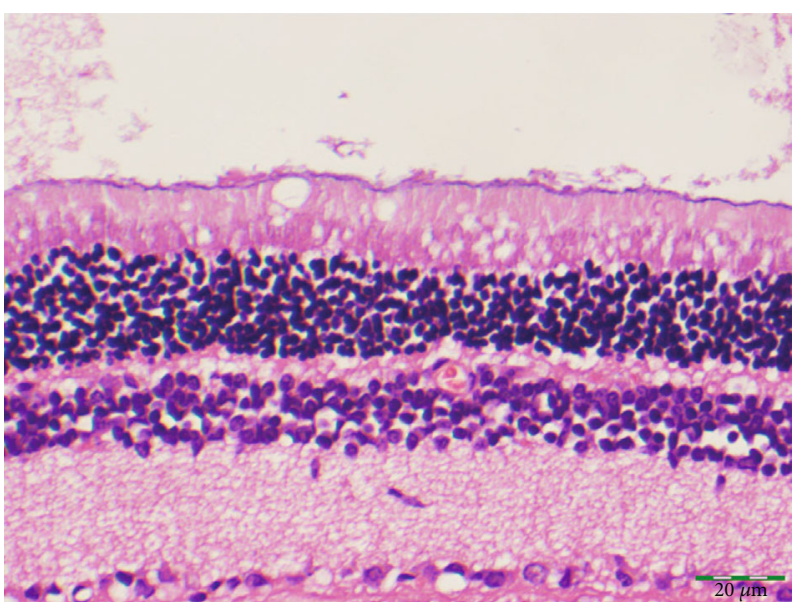

(a)

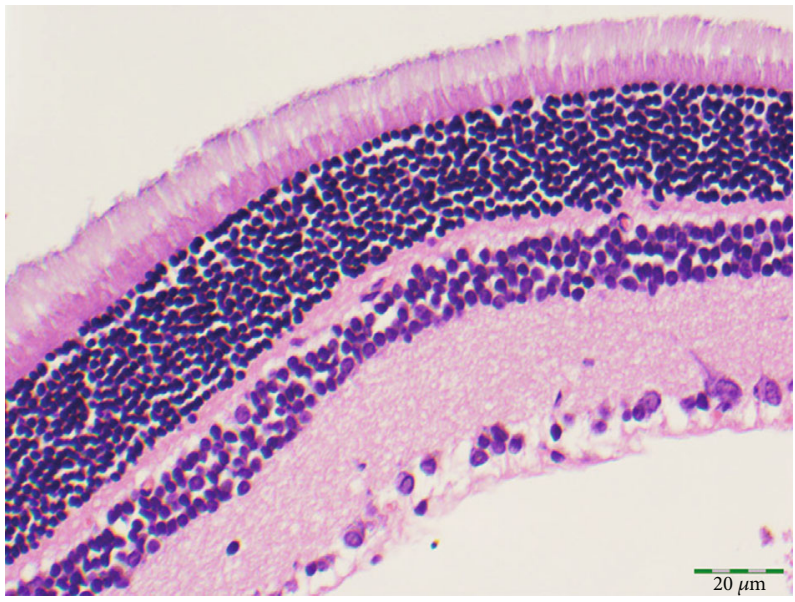

(c)

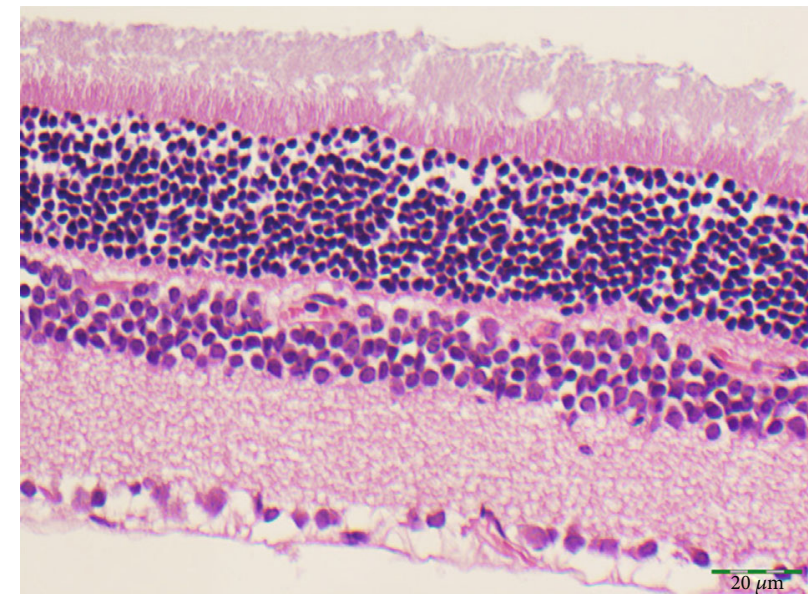

(b)

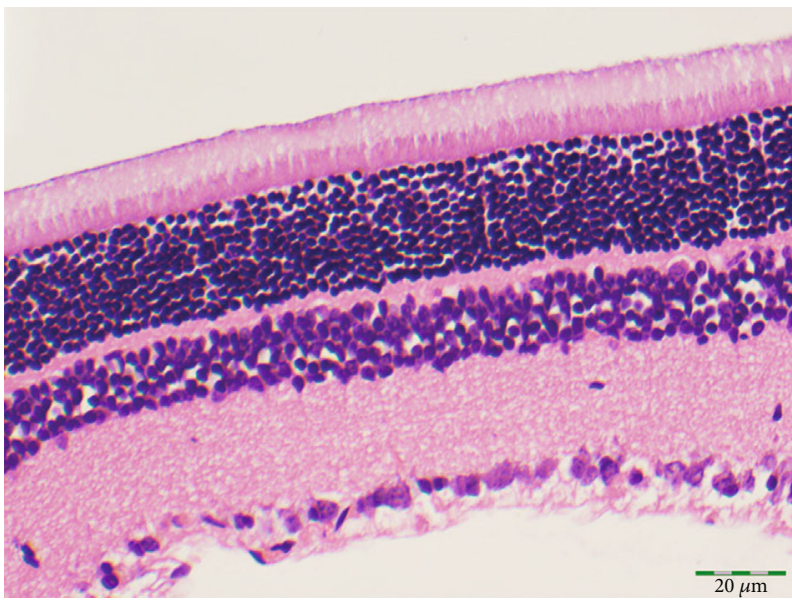

(d)

FIGURE 1: The histopathological appearance of the rat retinas exposed to the intense LED light-induced retinal degeneration between the groups. (a) Control. (b) RD. (c) RD+BCX1. (d) RD+BCX2. (H\&E X400), (Bar = $20 \mu \mathrm{m})$. BCX: $\beta$-cryptoxanthin; LED: light-emitting diode; $\mathrm{RD}$ : retinal degeneration.

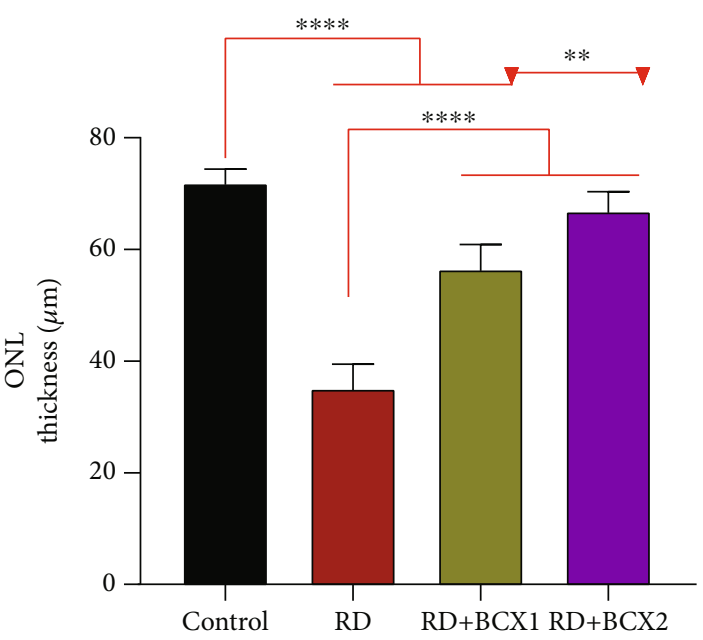

(a)

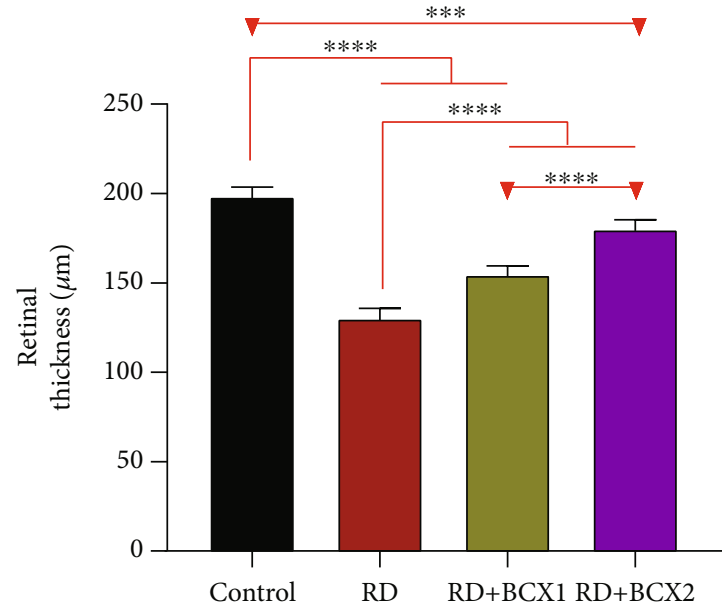

(b)

FIGURE 2: Treatment with $\beta$-cryptoxanthin (BCX) altered retinal morphology under intense LED light-exposed rats. (a) Quantification of the ONL thickness compared with the control. (b) Quantification of the Retinal thickness compared with the control $(n=7 ; P<.05)$. BCX: $\beta$ cryptoxanthin; LED: light-emitting diode; ONL: outer nuclear layer; RD: retinal degeneration. 


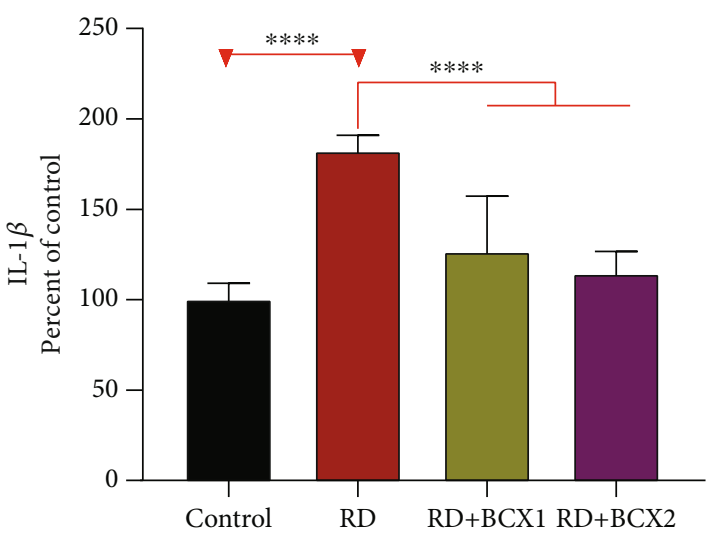

(a)

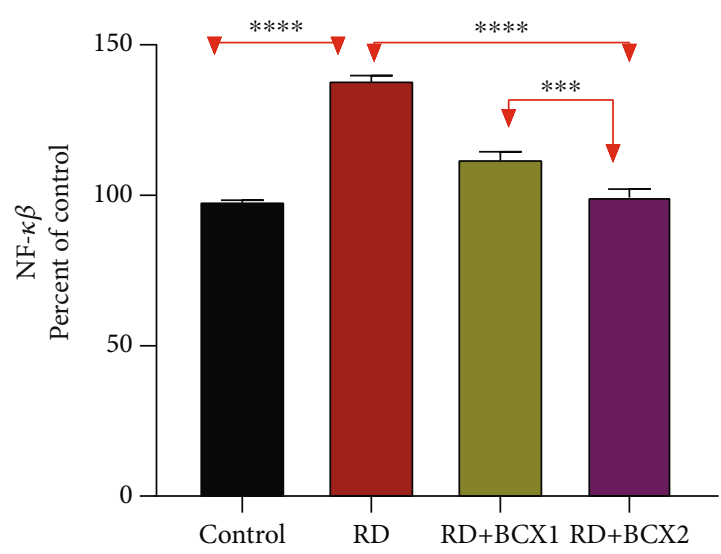

(c)

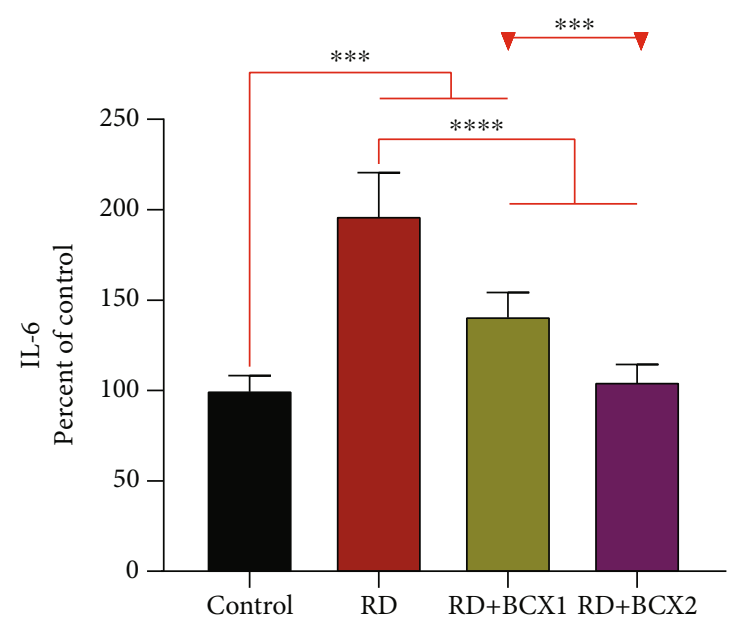

(b)

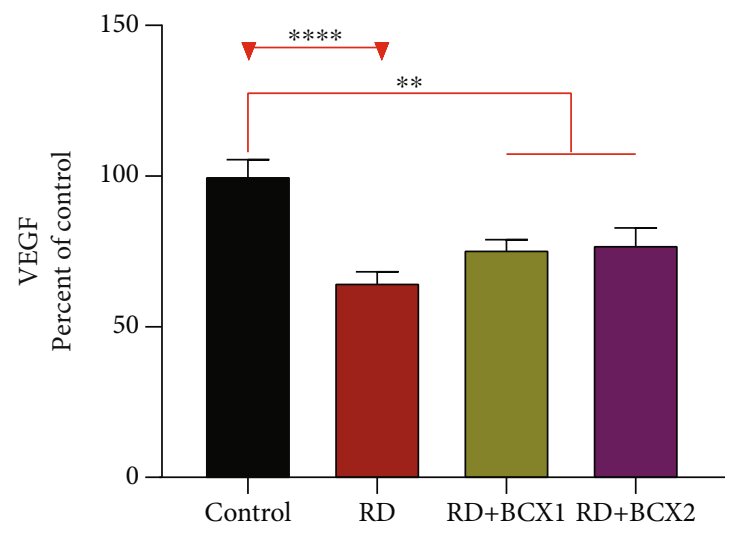

(d)

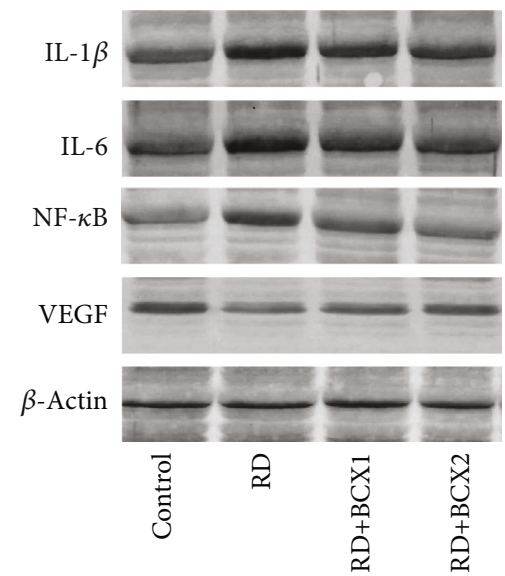

(e)

Figure 3: Effects of BCX on retinal protein levels of IL-1 $\beta$ (a), IL-6 (b), NF- $\kappa$ B (c), and VEGF (d) levels in rats with RD. The intensity of the western blot bands (e) was quantified by densitometric analysis, and $\beta$-actin was included to ensure equal protein loading. Data are expressed as a ratio of the control value (set to $100 \%)$. The bar represents the standard error of the mean. Blots were repeated at least three times $(n=3)$ and a representative blot is shown. Asterisks indicate statistical differences among groups $\left({ }^{* *} p<.01 ;{ }^{* * *} p<.001 ;{ }^{* * * *} p<.0001\right)$. BCX: $\beta$ Cryptoxanthin; IL-1 $\beta$ : interleukin-1 $\beta$; IL-6: interleukin-6; NF- $\kappa$ B: nuclear factor kappa B; RD: retinal degeneration; VEGF: vascular endothelial growth factor.

was no difference between BCX and control $(p>0.05)$. NCAM levels decreased in all groups compared to control $(p<0.001)$, while both BCX doses significantly increased
NCAM compared to the RD group $(p<0.001)$. While HO1 levels decreased in all groups compared to control $(p<0.001)$, BCX1 $\quad(p<0.05)$, and BCX2 $\quad(p<0.001)$ 


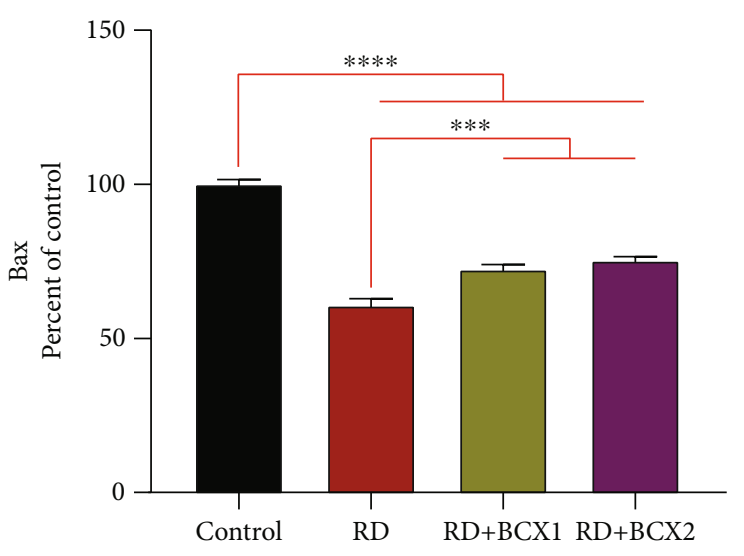

(a)

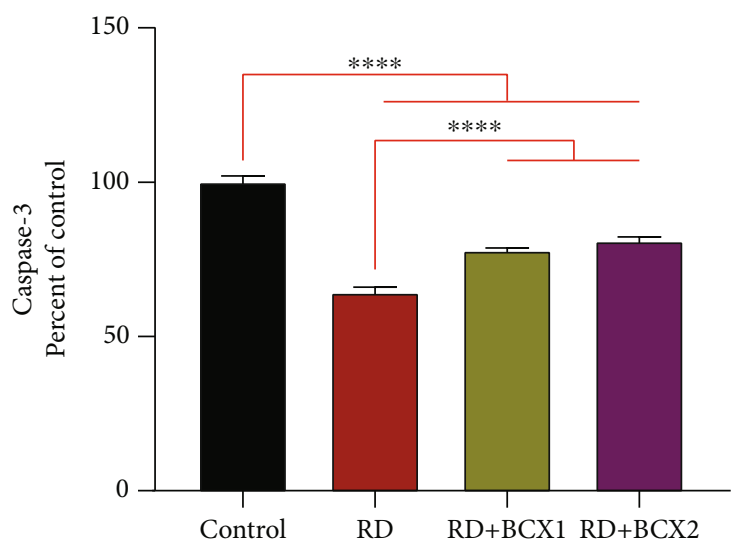

(c)

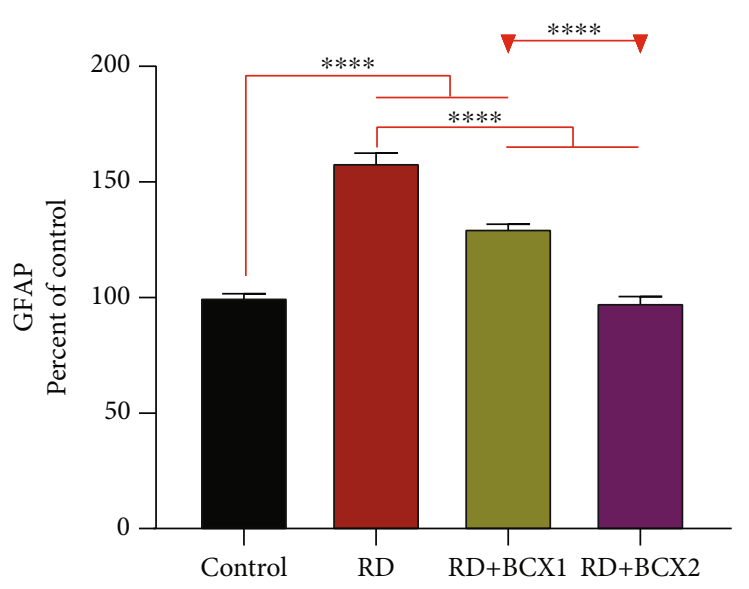

(e)

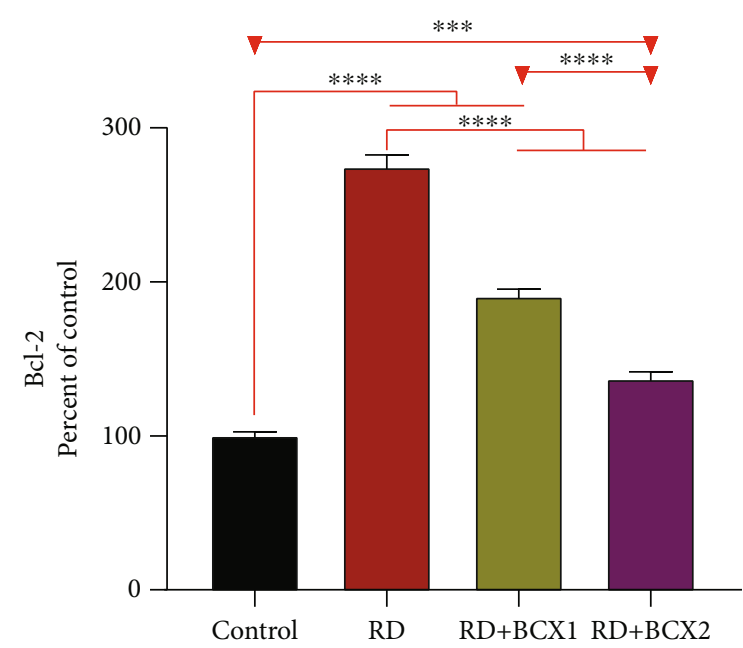

(b)

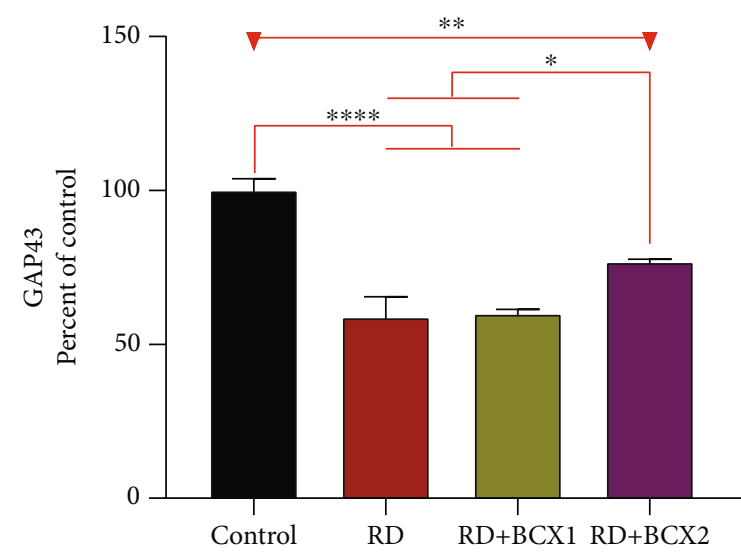

(d)

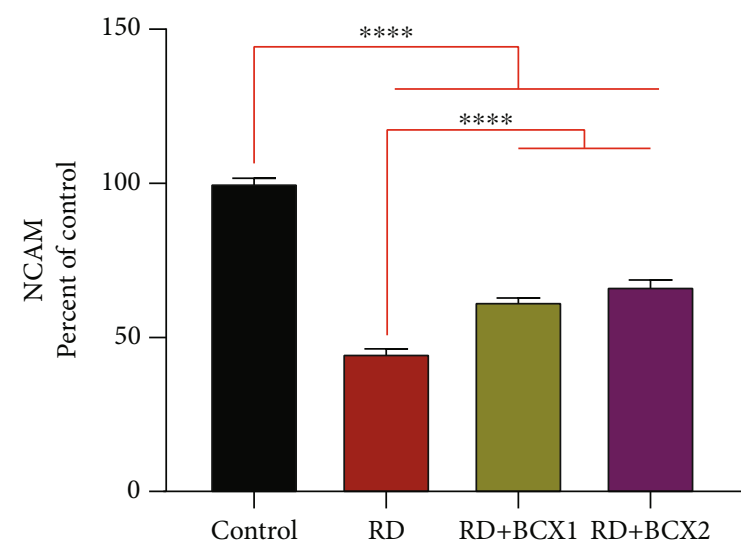

(f)

FIgURE 4: Continued. 


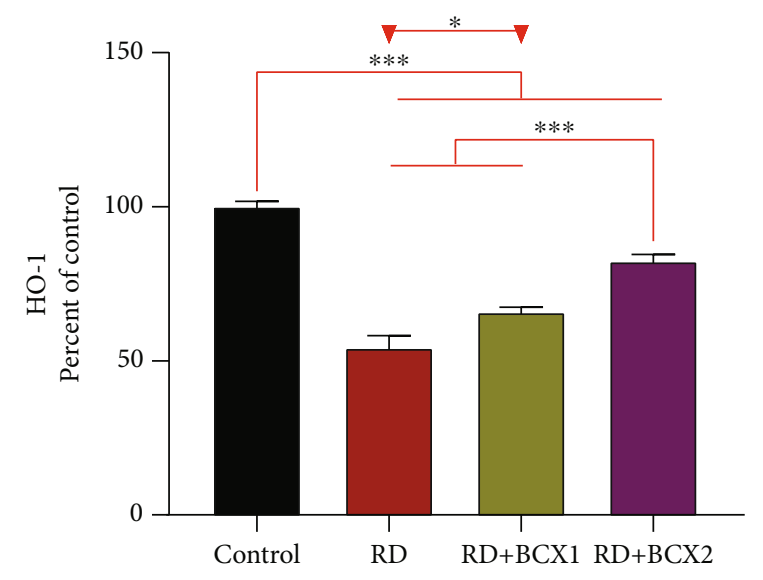

(g)

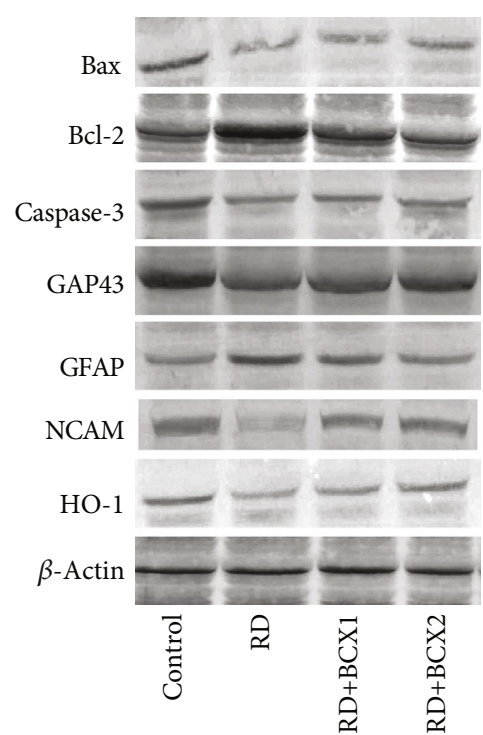

(h)

FIGURE 4: Effects of BCX on retinal protein levels of Bax (a), Bcl-2 (b), Caspase-3 (c), Gap43 (d), GFAP (e), NCAM (f) and HO-1 (g) levels in rats with RD. The intensity of the western blot bands (h) was quantified by densitometric analysis, and $\beta$-actin was included to ensure equal protein loading. Data are expressed as a ratio of the control value (set to 100\%). The bar represents the standard error of the mean. Blots were repeated at least three times $(n=3)$ and a representative blot is shown. Asterisks indicate statistical differences among groups $\left({ }^{*} p<.05 ;{ }^{* *}\right.$ $p<.01$; $\left.{ }^{* * *} p<.001 ; * * * * p<.0001\right)$. BCX: $\beta$-cryptoxanthin; Bax: Bcl-2-associated X; Bcl-2: B-cell lymphoma 2; Caspase-3: cysteineaspartic acid protease-3; GAP43: growth-associated protein 43; GFAP: glial fibrillary acidic protein; HO-1: heme oxygenase-1; NCAM: neural cell adhesion molecule; NF- $\kappa$ B: nuclear factor kappa B; RD: retinal degeneration.

significantly increased $\mathrm{HO} 1$ levels compared to $\mathrm{RD}$ group. The effects of two doses of BCXcel ${ }^{\mathrm{TM}}$ on ATF4, ATF6, and Grp78, Grp94 protein levels in rat retinas are shown in Figure 5. Accordingly, ATF4 and ATF6 levels significantly increased in all groups compared to the control group $(p<0.001)$. While this increase was reduced with BCXcel ${ }^{\mathrm{TM}}$ supplementation for both proteins, the lowest level was found in the BCX2 group, which was very close to the control $(p<0.05)$. In contrast, Grp78 levels increased in all groups compared to control $(p<0.001)$, and a significant decrease was observed in the BCX2 group when compared to the RD group and even BCX1 group $(p<0.001)$. In contrast, while Grp94 levels decreased significantly compared to control $(p<0.001)$, this decrease was found in the BCX2 group at the lowest level and close to control $(p<0.05)$.

\section{Discussion}

This study aimed to investigate the well-established provitamin A carotenoid, BCX, to limit LED-induced retinal damage, including its adverse consequences on metabolic markers and histopathological changes within the retina.

Reactive oxygen species (ROS) have been reported to cause cellular damage by attacking macromolecules in the visual cells when the intense light exposure time exceeds the threshold [31]. Two types of damage caused by light have earlier been proposed: the first contains rhodopsin and affects the photoreceptors; the second concerns retinal pigment epithelium (RPE), which is selectively vulnerable to high-energy blue light [21]. Excessive LED light exposure could lead to phototoxic effects because of the potent blue light hazard; accordingly, it can damage the macula $[9,32]$. However, macular degeneration is the primary cause of blindness and severe visual deterioration of older people over 65 [33].

MDA is a well-established marker of light-induced oxidative stress that is easily detectable in the retina. MDA is produced by photoreactive lipofuscin granules, which generate $\mathrm{H}_{2} \mathrm{O}_{2}$ and other potentially cytotoxic molecules in response to light in RPE [34,35]. Our study showed similar outcomes to long time constant (200 lux, 2 to 8 days) [36], or short time-intense (3,000 lux, 2 hours) [37], exposure to LED light both showed similar results such as photoreceptor cell deaths, remodeling of the retina and its cellular layers. In the $\mathrm{RD}$ group, the serum and retina lipid peroxidation marker, MDA, significantly increased, while the $\mathrm{BCXcel}^{\mathrm{TM}}$ consumption significantly reversed this effect of lipid peroxidation. This result parallels the findings of a recent study that showed LED exposure critically increases lipid peroxidation and 4-HNE production at the anterior segment level [38].

Our study has also clearly demonstrated that retina SOD, CAT, and GSH-Px activities and serum and retina retinol levels increased with BCXcel ${ }^{\mathrm{TM}}$ supplementation. Significant protective effects have also been characterized by both the increase of these BCX levels and the regulation of prominent protein levels as a result of the one-month BCX supplementations to the usual diet, which continued for 48 hours $(12 \mathrm{~h}$ light $/ 12 \mathrm{~h}$ dark) of intense LED light retinal degeneration. Using histopathological measurements, we also determined that retinal thickness, outer nuclear layer (ONL) thickness, and damaged retinal ganglion cell layers, which were 


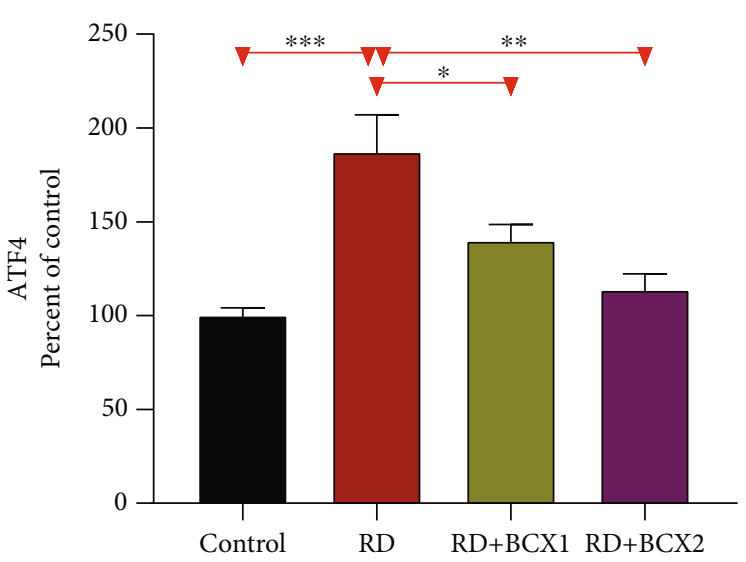

(a)

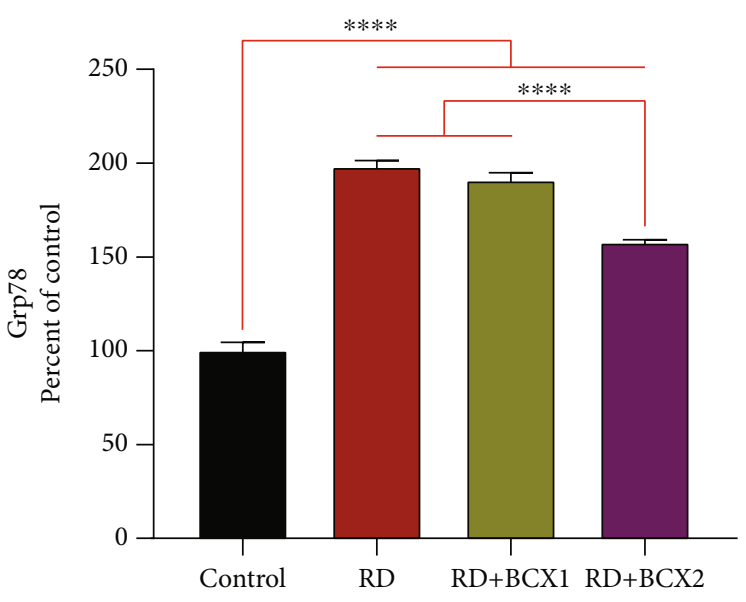

(c)

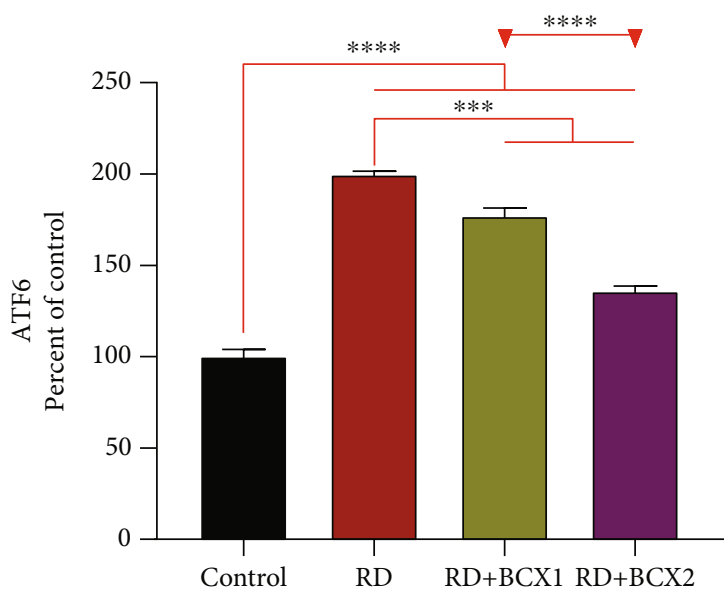

(b)

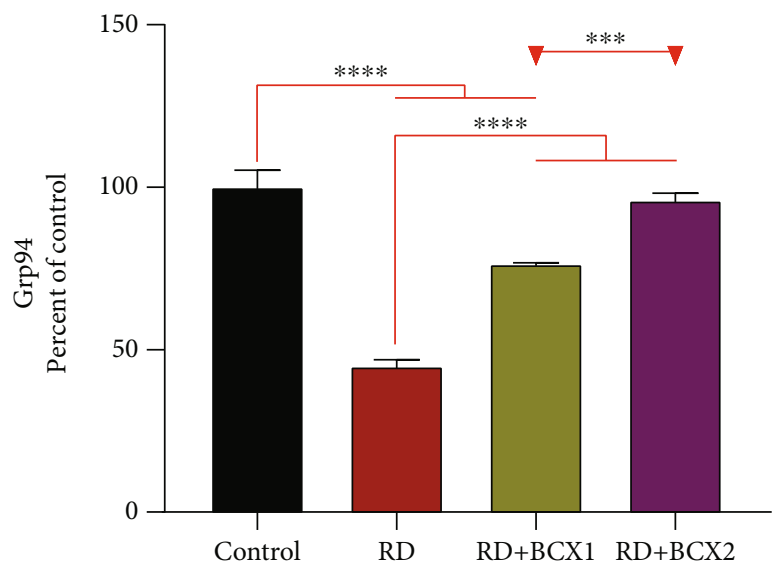

(d)

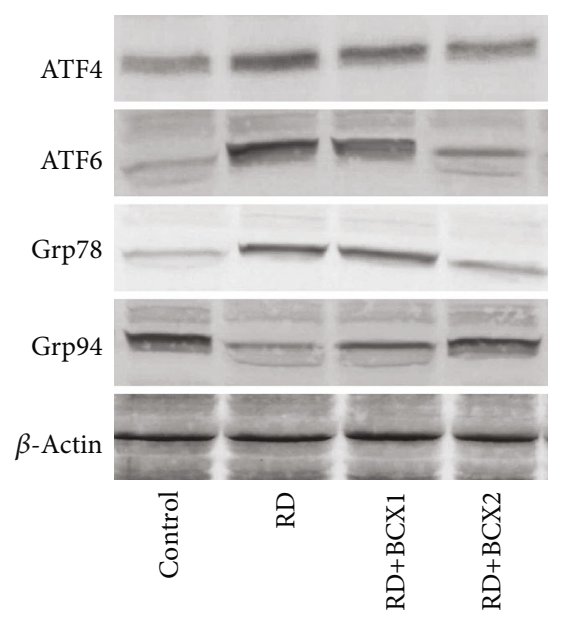

(e)

Figure 5: Effects of BCX on retinal protein expression of ATF4 (a), ATF6 (b), Grp78 (c), and Grp94 (d) levels in rats with RD. The intensity of the western blot bands (e) was quantified by densitometric analysis, and $\beta$-actin was included to ensure equal protein loading. Data are expressed as a ratio of the control value (set to $100 \%)$. The bar represents the standard error of the mean. Blots were repeated at least three times $(n=3)$ and a representative blot is shown. Asterisks indicate statistical differences among groups $\left({ }^{*} p<.05 ;{ }^{* *} p<.01 ;{ }^{* * *} p<\right.$ $\left..001{ }^{* * * *} p<.0001\right)$. ATF4: activating transcription factor 4; ATF6: activating transcription factor 4; BCX: $\beta$-cryptoxanthin; Grp78: glucose-regulated protein 78; Grp94: glucose-regulated protein 94; RD: retinal degeneration. 


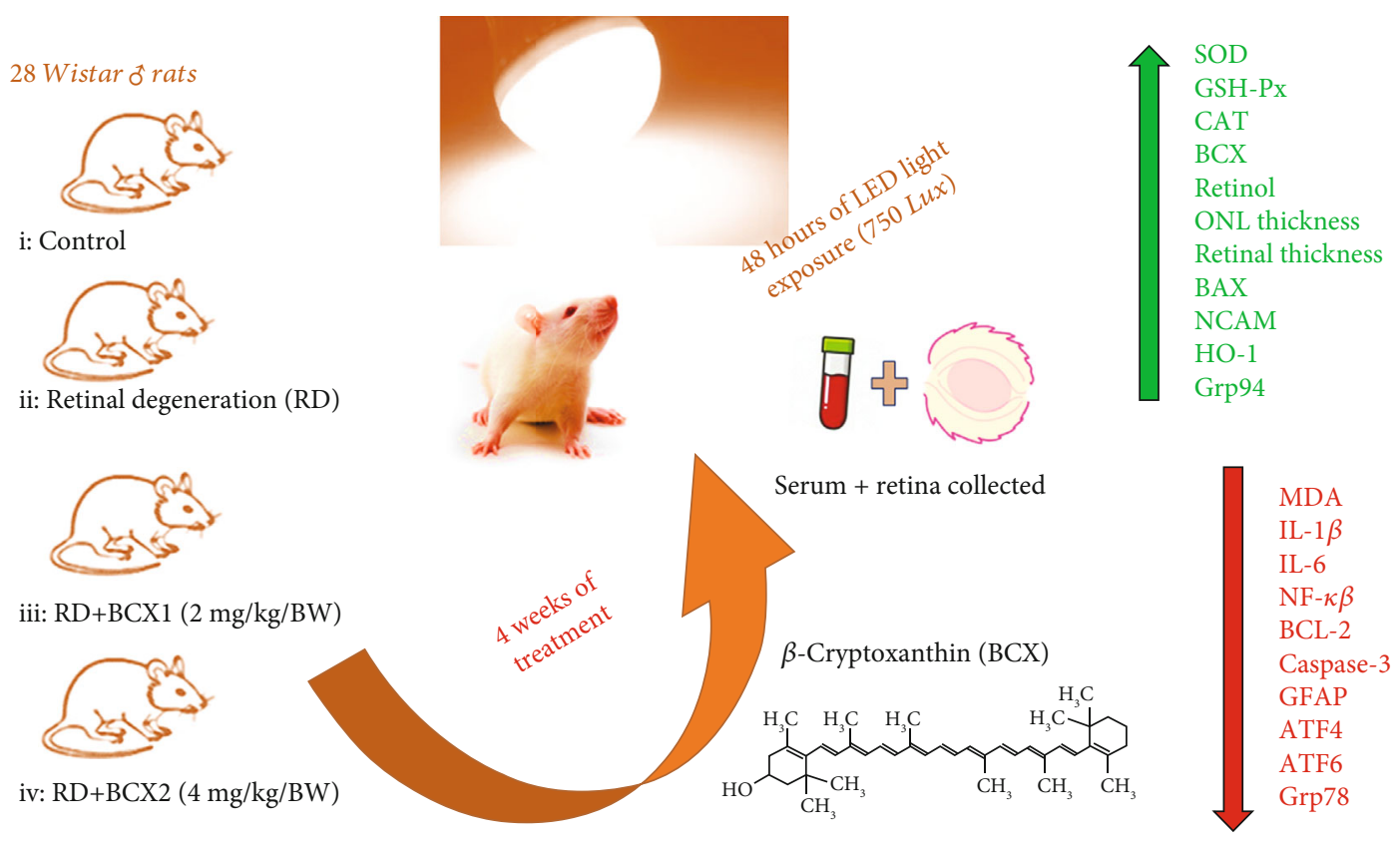

FIgURE 6: Study overview.

degenerated due to exposure to LED light, were preserved through BCXcel ${ }^{\mathrm{TM}}$ supplementation at both doses of BCX.

Inhibition of NF- $\kappa \mathrm{B}$ activation and downregulation of cellular inflammatory genes such as IL-1 family and IL-6 were proposed as unique retinal protection mechanisms during antioxidant treatments like curcumin [39]. NF- $\kappa \mathrm{B}$ is a transcription factor found in all cell types found inactive in the cytoplasm and can move to the nucleus when activated [40]. The IL-1 family is a cluster of 11 cytokines that induce a complex proinflammatory cytokine linkage plus control and initiate inflammatory responses over and done with the expression of integrins on leukocytes and endothelial cells [41]. IL-6 is an interleukin that functions as a proinflammatory cytokine and an anti-inflammatory myokine [42]. Contributors of the IL-1 family facilitate the photoreceptor cell death, inflammation, and angiogenesis in retinal degenerative diseases $[41,43]$, their reduction besides $\mathrm{NF}-\kappa \mathrm{B}$ in the retina has been significantly observed in the present study as the BCX supplement increased.

Vascular endothelial growth factor (VEGF) is a signal protein produced by cells that stimulate vasculogenesis and angiogenesis [44]. In this study, VEGF levels decreased in the RD group and did not statistically change with the addition of BCX. However, blue light is known to trigger inflammatory and angiogenic gene expressions in the early stages and has been reported to increase vascular endothelial growth factor (VEGF) secretion in A2E-loaded RPE cells [45]. In our study, if exposure to LED light was prolonged, BCX efficacy at these levels would be more noticeable as a ROS scavenger [46, 47].

We also observed that proapoptotic Bax and caspase-3 levels were decreased significantly in the RD group compared to control, which was reversed by BCX supplementation at both doses. The adverse effects of excessive LED damage on the antiapoptotic marker, $\mathrm{Bcl}-2$, were evident in the $\mathrm{RD}$ group but were reversed positively by $\mathrm{BCXce}^{\mathrm{TM}}$ supplementation. Photoreceptor cells were found to show intense light-induced apoptosis in chicks and albino fishes' retinas under constant intense light [20,48]. Similarly to our results, in a recent study in which ganglion cell injury was induced through experimental ocular glaucoma model in rats, it was shown that ocular hypertension provoked apoptosis via the intrinsic pathway, owing to Bax and caspase- 3 activation, in both retina and cornea, which also found to led DNA damage due to p53 activation [49]. As a result of antioxidant therapy, there was a suppression of proapoptotic markers and stimulation of antiapoptotic markers of ganglion cell damage, supporting antioxidants' role in reducing retinal damage [49, 50]. Contrary to the findings in the present study, the proapoptotic marker Bax was upregulated in the retina for up to 24 hours after a blast retinal damage study, whereas cytosolic Bax is shown to decrease 3 and 6 hours after retinal artery occlusion injury, while mitochondrial Bax levels rise at 3, 6, and 24 hours, indicating that Bax was settled in the mitochondria $[51,52]$. It was shown that degeneration of retinal capillaries under disease conditions could be reduced by antioxidant therapy through caspase- 3 and nuclear factor- $\kappa \mathrm{B}$ $(\mathrm{NF}-\kappa \mathrm{B})$ activation, which plays a vital role in retinal capillary apoptosis $[43,53]$.

BCX supplementation was able to reverse the 1.5 -fold increase in retina GFAP levels measured in the RD group. Indeed, increased GFAP levels have also been reported by de Raad and colleagues [54], who showed that GFAP accumulated in Müller cells in response to photoreceptor damage in the rat retina [54]. GFAP is upregulated during the light stress and blue light exposure, which leads to a nonspecific reactive change of Müller cells known as gliosis [55, 56]. However, GFAP accumulation in Müller cells was reported as an essential photoreceptor stress parameter in retinopathy induced rats, in accordance with our findings [57]. In a recent 
study, a pattern of GFAP ADPase staining also suggested a robust Müller cells/astrocytes reactivity in the GotoKakizaki rat retina [58]. In another novel study, a Chinese traditional antioxidant composition FSR prevented retinal thickness, including the ONL and retinal thickness in the diabetic rat retina, and similarly reduced the GFAP expressions in retinal tissues [59].

In the present study, retinal HO-1 levels decreased in the $\mathrm{RD}$ group, while the addition of $\mathrm{BCXcel}^{\mathrm{TM}}$ to the diet increased the levels similar to the control group. It is inversely proportional to an earlier report that created retinal damage via LED lights of different wavelengths and claimed that the iron ion load increased retinal damage in addition to oxidative stress and accordingly raised HO-1 levels [60]. In other studies similar to ours, HO-1 levels were found to be increased and protected light degeneration in the retina, while the antioxidant phytochemicals supported increased protection of the retina $[39,61]$.

Activating transcription factor 4 (ATF4) is the main component that encodes the cAMP response elementbinding transcription factor, stimulating cell survival via modulation of redox reactions, stress response, protein synthesis, and secretion $[62,63]$. ATF4 is triggered by stress signals such as anoxia/hypoxia, amino acid abstinence, endoplasmic reticulum stress, and oxidative stress [62]. Activating transcription factor 6 (ATF6) is a transmembrane protein located in the unfolded protein response in mammals and serves as a sensor for the endoplasmic reticulum homeostasis $[64,65]$. ATF6 is necessary to optimize protein folding, secretion, and degradation throughout the ER stress and, therefore, ease the improvement of acute stress and indulgence for chronic stress [66]. In our study, both ATF4 and ATF6 levels increased up to 2 times in the RD group compared to the control, and these levels decreased with $\mathrm{BCXcel}^{\mathrm{TM}}$ supplementation primarily via the higher dose. These data allude to one of the mechanisms by which $\mathrm{BCXcel}^{\mathrm{TM}}$ can protect against increased light stress, a commonly described mechanism of light-induced retinal damage $[67,68]$. Our findings also support that BCXcel ${ }^{\mathrm{TM}}$ supplementation normalized GRP78 and GRP94 levels to similar levels compared to the control group. It is proposed that ATF6 acts in synchronization with GRP78 and affects the response to stress, which is in line with the results obtained in our previous study (S. X. [69]). We also observed the increased levels of ER chaperone GRP94 via higher doses of BCXcel ${ }^{\mathrm{TM}}$ supplementation. This finding supported a previous report that BCX could positively modulate the stress response and was consistent with the requirement of maintaining hematopoietic stem cell interactions [70]. BCX has been revealed the upregulation of the energy metabolism, response to stress, reducing inflammation, and protein homeostasis as the primary metabolic objectives of this xanthophyll carotenoid [46].

\section{Conclusion}

In conclusion, oral supplementation of BCX has effectively demonstrated in our four weeks study that in a rat model, and $\mathrm{BCXCel}^{\mathrm{TM}}$ has a protective effect on high-intensity light- induced retinal damage by reducing oxidative stress and inflammation as well as protecting against mitochondrial DNA damage and cellular death (Figure 6). Present findings of this study on BCX doses have provided new in vivo evidence of the potential medicinal utilization of BCX in the suppression of diseases connected to intense LED toxicity on the retina and in those in which light has been considered a potential pathological inducer (e.g., AMD). Although MDA is an important oxidative stress marker, measuring MDA alone limits this study. In addition to MDA, measuring 8isoprostane and 4-hydroxynonenal (4-HNE) for protein oxidation and 8-hydroxy- 2 '-deoxyguanosine (8-OHdG) levels for DNA/RNA oxidation would further strengthen similar studies. Another limitation is that the animal data cannot be extrapolated directly to humans due to differences between nutrient requirements and the severity and duration of metabolism and dietary therapy. In conclusion, considering that LED lighting has been widely used, it is recommended to conduct more molecular studies using carotenoids as protective agents against the adverse effects of LED.

\section{Data Availability}

The data used to support the findings of this study are included within the article and the supplementary information files.

\section{Conflicts of Interest}

T. Namjoshi, V. Srivastava, A. Morde, M. Padigaru, and D. Rai are employed by OmniActive Health Technologies (Morristown, NJ, USA and Thane, India) company. The remaining authors declare no competing interests.

\section{Authors' Contributions}

K. Sahin and C. Orhan designed the research project. M. Tuzcu, H. Gencoglu, E. Sahin, and N. Sahin conducted the experiments. M. Tuzcu, H. Gencoglu, E. Sahin, N. Sahin, and I.H. Ozercan analyzed the experimental data. T. Namjoshi, V. Srivastava, and A. Morde involved in the design and optimization protocols for $\beta$-cryptoxanthin extraction followed by formulation strategy to ensure optimal bioavailability and efficacy. A Morde, M. Padigaru, and D. Rai were involved in the scientific evaluation of $\beta$-cryptoxanthin and identified biological relevance. H.Gencoglu, K. Sahin, M. Padigaru, and D. Rai wrote and edited the manuscript. All the authors read and approved the final manuscript.

\section{Acknowledgments}

The authors thank OmniActive Health Technologies (Morristown, NJ, USA and Thane, India) and the Turkish Academy of Science (in part, KS, Turkey). This work was supported by OmniActive Health Technologies (Morristown, NJ, USA, and Thane, India) and in part by the Turkish Academy of Science (Turkey). The funders had no role in the 
project design, data collection, data analyses, and interpretation.

\section{Supplementary Materials}

Figure 3 S1: (A-E) shows the full immunoblots related to Figure 3. Figure $3 \mathrm{~S} 1$ : $(\mathrm{A}-\mathrm{H})$ shows the full immunoblots related to Figure 3. Figure $3 \mathrm{~S}$ : (A-E) shows the full immunoblots related to Figure 5. (Supplementary Materials)

\section{References}

[1] I. Bellezza, "Oxidative stress in age-related macular degeneration: Nrf2 as therapeutic target," Frontiers in Pharmacology, vol. 9, p. 1280, 2018.

[2] P. Wong, M. Markey, C. M. Rapp, R. M. Darrow, A. Ziesel, and D. T. Organisciak, "Enhancing the efficacy of AREDS antioxidants in light-induced retinal degeneration," Molecular Vision, vol. 23, pp. 718-739, 2017.

[3] C. A. Curcio, "Soft drusen in age-related macular degeneration: biology and targeting via the oil spill strategies," Investigative Ophthalmology \& Visual Science, vol. 59, no. 4, pp. AMD160-AMD181, 2018.

[4] K. Kaarniranta, E. Pawlowska, J. Szczepanska, A. Jablkowska, and J. Blasiak, "Role of mitochondrial DNA damage in ROSmediated pathogenesis of age-related macular degeneration (AMD)," International Journal of Molecular Sciences, vol. 20, no. 10 , p. 2374, 2019.

[5] D. Ali, R. S. Ray, and R. K. Hans, "UVA-induced cyototoxicity and DNA damaging potential of benz (e) acephenanthrylene," Toxicology Letters, vol. 199, no. 2, pp. 193-200, 2010.

[6] D. Ali, A. Verma, F. Mujtaba, A. Dwivedi, R. K. Hans, and R. S. Ray, "UVB-induced apoptosis and DNA damaging potential of chrysene via reactive oxygen species in human keratinocytes," Toxicology Letters, vol. 204, no. 2-3, pp. 199-207, 2011.

[7] M. Wong-Riley, "Energy metabolism of the visual system," Eye and Brain, vol. 2, no. 7, pp. 99-116, 2010.

[8] R. A. Kowluru and P.-S. Chan, "Oxidative stress and diabetic retinopathy," Experimental Diabetes Research, vol. 2007, Article ID 43603, 12 pages, 2007.

[9] I. Jaadane, G. E. V. Rodriguez, P. Boulenguez et al., "Effects of white light-emitting diode (LED) exposure on retinal pigment epithelium in vivo," Journal of Cellular and Molecular Medicine, vol. 21, no. 12, pp. 3453-3466, 2017.

[10] X. Gong, C. S. Draper, G. S. Allison, R. Marisiddaiah, and L. P. Rubin, "Effects of the macular carotenoid lutein in human retinal pigment epithelial cells," Antioxidants, vol. 6, no. 4, p. 100, 2017.

[11] K. J. McClinton, M. Aliani, S. Kuny, Y. Sauvé, and M. Suh, "Differential effect of a carotenoid-rich diet on retina function in non-diabetic and diabetic rats," Nutritional Neuroscience, vol. 23, no. 11, pp. 838-848, 2020.

[12] K. Sahin, F. Akdemir, C. Orhan et al., “(3R, 3’R)-zeaxanthin protects the retina from photo-oxidative damage via modulating the inflammation and visual health molecular markers," Cutaneous and Ocular Toxicology, vol. 38, no. 2, pp. 161168, 2019.

[13] W. Stahl, "Macular carotenoids: lutein and zeaxanthin," Developments in Ophthalmology, vol. 38, pp. 70-88, 2005.

[14] A. Junghans, H. Sies, and W. Stahl, "Macular pigments lutein and zeaxanthin as blue light filters studied in liposomes,"
Archives of Biochemistry and Biophysics, vol. 391, no. 2, pp. 160-164, 2001.

[15] M. Eggersdorfer and A. Wyss, "Carotenoids in human nutrition and health," Archives of Biochemistry and Biophysics, vol. 652, pp. 18-26, 2018.

[16] B. J. Burri, M. R. La Frano, and C. Zhu, “Absorption, metabolism, and functions of $\beta$-Cryptoxanthin," Nutrition Reviews, vol. 74, no. 2, pp. 69-82, 2016.

[17] J. Widomska, M. Zareba, and W. K. Subczynski, "Can xanthophyll-membrane interactions explain their selective presence in the retina and brain?," Foods (Basel, Switzerland), vol. 5, no. 4, p. 7, 2016.

[18] J. Amengual, M. Airanthi, K. Widjaja-Adhi et al., "Two Carotenoid Oxygenases Contribute to Mammalian Provitamin A Metabolism," The Journal of Biological Chemistry, vol. 288, no. 47, pp. 34081-34096, 2013.

[19] J. Coronel, I. Pinos, and J. Amengual, “ $\beta$-carotene in obesity research: technical considerations and current status of the field," Nutrients, vol. 11, no. 4, p. 842, 2019.

[20] K. A. Jha, T. C. Nag, V. Kumar et al., "Differential expression of AQP1 and AQP4 in avascular chick retina exposed to moderate light of variable photoperiods," Neurochemical Research, vol. 40, no. 11, pp. 2153-2166, 2015.

[21] D. T. Organisciak and D. K. Vaughan, "Retinal light damage: mechanisms and protection," Progress in Retinal and Eye Research, vol. 29, no. 2, pp. 113-134, 2010.

[22] B. J. Burri, "Beta-cryptoxanthin as a source of vitamin A," Journal of the Science of Food and Agriculture, vol. 95, no. 9, pp. 1786-1794, 2015.

[23] R. Arantes-Rodrigues, A. Henriques, R. Pinto-Leite et al., "The effects of repeated oral gavage on the health of male CD-1 mice," Lab Animal, vol. 41, no. 5, pp. 129-134, 2012.

[24] K. Sahin, H. Gencoglu, F. Akdemir et al., "Lutein and zeaxanthin isomers may attenuate photo-oxidative retinal damage via modulation of $\mathrm{G}$ protein-coupled receptors and growth factors in rats," Biochemical and Biophysical Research Communications, vol. 516, no. 1, pp. 163-170, 2019.

[25] O. Barim and M. Karatepe, "The effects of pollution on the vitamins A, E, C, beta-carotene contents and oxidative stress of the freshwater crayfish, Astacus leptodactylus," Ecotoxicology and Environmental Safety, vol. 73, no. 2, pp. 138-142, 2010.

[26] M. Karatepe, "Simultaneous determination of ascorbic acid and free malondialdehyde in human serum by HPLC-UV," LC-GC North America, vol. 22, no. 4, pp. 362-365, 2004.

[27] R. J. Collier, W. Yu, S. S. Smith et al., "Complement deposition and microglial activation in the outer retina in light-induced retinopathy: inhibition by a 5-HT1AAgonist," Investigative Ophthalmology \& Visual Science, vol. 52, no. 11, pp. 81088116, 2011.

[28] C. Orhan, F. Akdemir, M. Tuzcu et al., "Mesozeaxanthin protects retina from oxidative stress in a rat model," Journal of Ocular Pharmacology and Therapeutics, vol. 32, no. 9, pp. 631-637, 2016.

[29] M. Ulas, C. Orhan, M. Tuzcu et al., "Anti-diabetic potential of chromium histidinate in diabetic retinopathy rats," $B M C$ Complementary and Alternative Medicine, vol. 15, no. 1, p. 16, 2015.

[30] F. Faul, E. Erdfelder, A.-G. Lang, and A. Buchner, " $G *$ Power 3: a flexible statistical power analysis program for the social, behavioral, and biomedical sciences," Behavior Research Methods, vol. 39, no. 2, pp. 175-191, 2007. 
[31] B. Aydin, D. Erdem, S. Necat Yilmaz et al., "Retinal endoilluminator toxicity of xenon and light-emitting diode (LED) light source: rabbit model," Cutaneous and Ocular Toxicology, vol. 33, no. 3, pp. 192-196, 2013.

[32] P. N. Youssef, N. Sheibani, and D. M. Albert, "Retinal light toxicity," Eye, vol. 25, no. 1, pp. 1-14, 2011.

[33] S. B. Bressler and N. M. Bressler, "Chapter 65 - age-related macular degeneration: non-neovascular early AMD, intermediate AMD, and geographic atrophy," in Retina (Fifth Edition), S. J. Ryan, S. V. R. Sadda, D. R. Hinton, A. P. Schachat, S. V. R. Sadda, C. P. Wilkinson, P. Wiedemann, and A. P. Schachat, Eds., pp. 1150-1182, W.B. Saunders, London, 2013.

[34] V. E. Baksheeva, V. V. Tiulina, N. K. Tikhomirova et al., "Suppression of light-induced oxidative stress in the retina by mitochondria-targeted antioxidant," Antioxidants, vol. 8, no. 1, p. 3, 2019.

[35] M. Rózanowska, J. Jarvis-Evans, W. Korytowski, M. E. Boulton, J. M. Burke, and T. Sarna, "Blue light-induced reactivity of retinal age pigment. In vitro generation of oxygen-reactive species," The Journal of Biological Chemistry, vol. 270, no. 32, pp. 18825-18830, 1995.

[36] Q. Wei, X. Liang, Y. Peng et al., “ $17 \beta$-estradiol ameliorates oxidative stress and blue light-emitting diode-induced retinal degeneration by decreasing apoptosis and enhancing autophagy," Drug Design, Development and Therapy, vol. 12, pp. 2715-2730, 2018.

[37] M. M. Benedetto, M. E. Guido, and M. A. Contin, "Non-visual photopigments effects of constant light-emitting diode light exposure on the inner retina of Wistar rats," Frontiers in Neurology, vol. 8, p. 417, 2017.

[38] I. Jun, S. J. Han, H.-S. Shin et al., "Comparison of ophthalmic toxicity of light-emitting diode and organic light-emitting diode light sources," Scientific Reports, vol. 10, no. 1, p. 11582, 2020.

[39] M. N. A. Mandal, J. M. R. Patlolla, L. Zheng et al., "Curcumin protects retinal cells from light-and oxidant stress-induced cell death," Free Radical Biology \& Medicine, vol. 46, no. 5, pp. 672-679, 2009.

[40] A. Oeckinghaus and S. Ghosh, "The NF- $\kappa$ B family of transcription factors and its regulation," Cold Spring Harbor Perspectives in Biology, vol. 1, no. 4, article a000034, 2009.

[41] C. A. Dinarello, "Overview of the IL-1 family in innate inflammation and acquired immunity," Immunological Reviews, vol. 281, no. 1, pp. 8-27, 2018.

[42] J. J. Fuster and K. Walsh, "The good, the bad, and the ugly of Interleukin-6 signaling," The EMBO Journal, vol. 33, no. 13, pp. 1425-1427, 2014.

[43] C. Li, X. Miao, F. Li et al., "Oxidative stress-related mechanisms and antioxidant therapy in diabetic retinopathy," Oxidative Medicine and Cellular Longevity, vol. 2017, Article ID 9702820, 15 pages, 2017.

[44] C. J. Peach, V. W. Mignone, M. A. Arruda et al., "Molecular pharmacology of VEGF-A isoforms: binding and signalling at VEGFR2," International Journal of Molecular Sciences, vol. 19, no. 4, p. 1264, 2018.

[45] C.-H. Lin, M.-R. Wu, W.-J. Huang, D. S.-L. Chow, G. Hsiao, and Y.-W. Cheng, "Low-luminance blue light-enhanced phototoxicity in A2E-laden RPE cell cultures and rats," International Journal of Molecular Sciences, vol. 20, no. 7, p. 1799, 2019.

[46] S. Llopis, M. J. Rodrigo, N. González et al., “ $\beta$-Cryptoxanthin reduces body fat and increases oxidative stress response in
Caenorhabditis elegans model," Nutrients, vol. 11, no. 2, p. 232, 2019.

[47] E. Pawlowska, J. Szczepanska, A. Koskela, K. Kaarniranta, and J. Blasiak, "Dietary polyphenols in age-related macular degeneration: protection against oxidative stress and beyond," Oxidative Medicine and Cellular Longevity, vol. 2019, Article ID 9682318, 13 pages, 2019.

[48] R. Bejarano-Escobar, M. Blasco, G. Martín-Partido, and J. Francisco-Morcillo, "Light-induced degeneration and microglial response in the retina of an epibenthonic pigmented teleost: age-dependent photoreceptor susceptibility to cell death," Journal of Experimental Biology, vol. 215, no. 21, pp. 3799-3812, 2012.

[49] Z. Erisgin, M. A. Ozer, M. Tosun, S. Ozen, and S. Takir, "The effects of intravitreal $\mathrm{H} 2 \mathrm{~S}$ application on apoptosis in the retina and cornea in experimental glaucoma model," International Journal of Experimental Pathology, vol. 100, no. 5-6, pp. 330-336, 2020.

[50] D. Cervia, E. Catalani, and G. Casini, "Neuroprotective peptides in retinal disease," Journal of Clinical Medicine, vol. 8, no. 8, p. 1146, 2019.

[51] C. N. Thomas, M. Berry, A. Logan, R. J. Blanch, and Z. Ahmed, "Caspases in retinal ganglion cell death and axon regeneration," Cell Death Discovery, vol. 3, no. 1, pp. 1-13, 2017.

[52] Y. Zhang, C.-H. Cho, L.-o. Atchaneeyasakul, T. McFarland, B. Appukuttan, and J. Timothy Stout, "Activation of the mitochondrial apoptotic pathway in a rat model of central retinal artery occlusion," Investigative Ophthalmology \& Visual Science, vol. 46, no. 6, pp. 2133-2139, 2005.

[53] R. A. Kowluru, P. Koppolu, S. Chakrabarti, and S. Chen, "Diabetes-induced activation of nuclear transcriptional factor in the retina, and its inhibition by antioxidants," Free Radical Research, vol. 37, no. 11, pp. 1169-1180, 2009.

[54] S. Raadde, P. J. Szczesny, K. Munz, and C. E. Remé, "Light damage in the rat retina: glial fibrillary acidic protein accumulates in Müller cells in correlation with photoreceptor damage," Ophthalmic Research, vol. 28, no. 2, pp. 99-107, 1996.

[55] C. L. Gupta, T. C. Nag, K. A. Jha et al., "Changes in the inner retinal cells after intense and constant light exposure in Sprague-Dawley rats," Photochemistry and Photobiology, vol. 96, no. 5, pp. 1061-1073, 2020.

[56] I. Iandiev, A. Wurm, M. Hollborn et al., "Müller cell response to blue light injury of the rat retina," Investigative Ophthalmology \& Visual Science, vol. 49, no. 8, pp. 3559-3567, 2008.

[57] E. Jung and J. Kim, "Aloin inhibits Müller cells swelling in a rat model of thioacetamide-induced hepatic retinopathy," Molecules (Basel, Switzerland), vol. 23, no. 11, article 2806, 2018.

[58] S. Hachana, M. Pouliot, R. Couture, and E. Vaucher, "Diabetes-induced inflammation and vascular alterations in the Goto-Kakizaki rat retina," Current Eye Research, vol. 45, no. 8, pp. 965-974, 2020.

[59] M. He, L. Pan, L. Guo, M. Zhang, S. Wang, and H. He, "Fushiming capsule attenuates diabetic rat retina damage via antioxidation and anti-inflammation," Evidence-based Complementary and Alternative Medicine: Ecam, vol. 2019, article 5376439, 13 pages, 2019.

[60] Y.-M. Shang, G.-S. Wang, D. H. Sliney, C.-H. Yang, and L.L. Lee, "Light-emitting-diode induced retinal damage and its wavelength dependency in vivo," International Journal of Ophthalmology, vol. 10, no. 2, pp. 191-202, 2017. 
[61] T. Okamoto, H. Kawashima, H. Osada et al., "Dietary spirulina supplementation protects visual function from photostress by suppressing retinal neurodegeneration in mice," Translational Vision Science \& Technology, vol. 8, no. 6, p. 20, 2019.

[62] K. Ameri and A. L. Harris, "Activating transcription factor 4," The International Journal of Biochemistry \& Cell Biology, vol. 40, no. 1, pp. 14-21, 2008.

[63] S. E. Kobylewski, K. A. Henderson, K. E. Yamada, and C. D. Eckhert, "Activation of the EIF2 $\alpha /$ ATF4 and ATF6 pathways in DU-145 cells by boric acid at the concentration reported in men at the US mean boron intake," Biological Trace Element Research, vol. 176, no. 2, pp. 278-293, 2017.

[64] M. Carrara, F. Prischi, and M. Ali, "UPR signal activation by luminal sensor domains," International Journal of Molecular Sciences, vol. 14, no. 3, pp. 6454-6466, 2013.

[65] D. R. Hyduke, S. A. Amundson, and A. J. Fornace, "Chapter 257 - complexity of stress signaling," in Handbook of Cell Signaling (Second Edition), R. A. Bradshaw and E. A. Dennis, Eds., pp. 2107-2125, Academic Press, San Diego, 2010.

[66] B. M. Gardner, D. Pincus, K. Gotthardt, C. M. Gallagher, and P. Walter, "Endoplasmic reticulum stress sensing in the unfolded protein response," Cold Spring Harbor Perspectives in Biology, vol. 5, no. 3, p. a013169, 2013.

[67] M. E. Fusakio, J. A. Willy, Y. Wang et al., "Transcription factor ATF4 directs basal and stress-induced gene expression in the unfolded protein response and cholesterol metabolism in the liver," Molecular Biology of the Cell, vol. 27, no. 9, pp. 1536$1551,2016$.

[68] R. F. Hillary and U. FitzGerald, "A lifetime of stress: ATF6 in development and homeostasis," Journal of Biomedical Science, vol. 25, no. 1, p. 48, 2018.

[69] S. X. Zhang, E. Sanders, S. J. Fliesler, and J. J. Wang, "Endoplasmic reticulum stress and the unfolded protein responses in retinal degeneration," Experimental Eye Research, vol. 125, no. 8, pp. 30-40, 2014.

[70] B. Luo, B. S. Lam, S. H. Lee et al., "The endoplasmic reticulum chaperone protein GRP94 is required for maintaining hematopoietic stem cell interactions with the adult bone marrow niche," PLoS One, vol. 6, no. 5, article e20364, 2011.

[71] NRC (US), Nutrient Requirements of Laboratory Animals: Fourth Revised Edition, 1995, National Academies Press (US), Washington (DC), 1995, https://www.ncbi.nlm.nih .gov/books/NBK231927/. 